\title{
Monetary Policy in a Small Open Economy with a Preference for Robustness
}

\author{
Richard Dennis
}

Kai Leitemo

May 2007

\begin{abstract}
We use robust control techniques to study the effects of model uncertainty on monetary policy in an estimated small-open-economy model of the U.K. Compared to the closed economy, the presence of an exchange rate channel for monetary policy not only produces new trade-offs for monetary policy, but it also introduces an additional source of specification errors. We find that exchange rate shocks are an important contributor to volatility in the model, and that the exchange rate equation is particularly vulnerable to model misspecification, along with the equation for domestic inflation. However, when policy is set with discretion, the cost of insuring against model misspecification appears reasonably small.
\end{abstract}

Keywords: Model uncertainty, Model misspecification, Robust control.

JEL Classification: E52, E61, F41.

\footnotetext{
*Dennis: Federal Reserve Bank of San Francisco, richard.dennis@sf.frb.org; Leitemo: Norwegian School of Management (BI), kai.leitemo@bi.no; Söderström: IGIER, Bocconi University, ulf.soderstrom@unibocconi.it. We are grateful for comments from Eleni Angelopoulou, Gino Cateau, Maria Demertzis, Juha Kilponen, Lars Svensson, and seminar participants at Sveriges Riksbank, the University of Brescia, the Bank of Italy, De Nederlandsche Bank, the Finnish Economic Society Meeting in Helsinki, February 2006, the 10th International Conference on Macroeconomic Analysis and International Finance in Rethymno, Crete, May 2006, the Oslo Conference on Monetary Policy and Uncertainty, June 2006, and the 12th International Conference on Computing in Economics and Finance in Limassol, Cyprus, June 2006. We would also like to thank Anita Todd for editorial suggestions. The second author thanks the Norwegian Financial Market Fund for financial support. The views expressed in this paper do not necessarily reflect those of the Federal Reserve Bank of San Francisco or the Federal Reserve System.
} 


\section{Introduction}

Although the canonical New Keynesian model (Goodfriend and King (1997), Clarida, Galí, and Gertler (1999), and Woodford (2003)) is used extensively to analyze monetary policy, important questions about its structure remain unresolved. For instance, there are ongoing debates about the role of forward-looking inflation expectations, and the nature of the driving variable - real marginal cost or an output gap - in the New Keynesian Phillips curve, and about the importance of habit formation and consumption smoothing in the forward-looking "IS" curve. More generally, it is widely understood among practitioners that monetary policy affects the economy with "long and variable lags" in ways that many models do not acknowledge.

Of course, these debates about the appropriate structure of closed-economy New Keynesian models apply equally to open-economy specifications. After all, the transmission mechanisms and the monetary policy channels that operate in open-economy models are often similar to those operating in closed-economy specifications. However, unlike in the closed economy, in the open economy there can be concerns about the level of exchange rate pass-through, concerns centered around whether pass-through is full or partial, and about the extent to which imports are consumed or employed as intermediate inputs in the production of domestic goods. Similarly, exchange rate dynamics are difficult to model and from an empirical standpoint there is good reason to view uncovered interest rate parity with suspicion. Importantly, these concerns extend beyond parameter uncertainty, amounting to a concern about the very structure of the model used to describe the economy.

We study the conduct of monetary policy in a model of a small open economy estimated on U.K. data. Unlike most papers that consider the design of monetary policy in openeconomy contexts, we introduce a concern for model misspecification on the part of the central bank and focus on policy rules that have been formulated purposefully to be robust to model misspecification. In the tradition of Hansen and Sargent (2007), we assume that the central bank possesses a benchmark model of the economy, which it is concerned may be misspecified, but that it is unwilling to posit a probability distribution over possible specification errors. The central bank allows for specification errors that lie within a neighborhood of its benchmark specification and conducts monetary policy to guard against the worst-case specification error. In taking this approach, the central bank recognizes that its policy will be suboptimal if its benchmark model is actually specified correctly, but it still conducts policy this way, gaining comfort from the knowledge that by doing so it is insuring against catastrophic outcomes.

The open-economy model that we consider is based on the theoretical model of Mona- 
celli (2005). The model allows households to consume goods produced both domestically and abroad, with sticky prices in both the domestic and the import sector. Sticky import prices imply that exchange rate movements do not feed directly through to consumer prices, that is, exchange rate pass-through is incomplete. The model also allows a portfolio allocation choice between domestic and foreign bonds, giving rise to an uncovered interest rate parity (UIP) condition and making the exchange rate an important channel for monetary policy and risk premium shocks an important source of economic volatility. As we show, the exchange rate channel introduces additional trade-offs that the central bank must acknowledge when formulating policy, and it introduces an additional location for possible model misspecification.

We contrast the sources of misspecification and the design of robust monetary policy in several versions of our model: a closed-economy version, a version with open-economy transmission channels but only domestic shocks, and versions with shocks emanating from the open-economy components of the model. We show that in a closed economy, a robust central bank should be concerned mainly with specification errors to the inflation equation (or Phillips curve). This finding is consistent with previous studies, e.g., Dennis, Leitemo, and Söderström (2006) and Leitemo and Söderström (2004).

Adding open-economy transmission channels and shocks, we find that, while imported inflation and foreign output are relatively unimportant sources of misspecification, shocks to the UIP condition ("exchange rate shocks") are very important for generating volatility, and the UIP condition is a particularly damaging location for model misspecification. This is partly because the UIP condition is subject to large risk premium shocks and partly because the exchange rate has a direct impact on all other variables in the model and therefore presents the central bank with a challenging trade-off when responding to shocks. We conclude that a central bank worried about model misspecification should be concerned about the UIP condition, but also about the equation for domestic inflationthe open-economy Phillips curve - just as in the closed economy.

Our approach to robust monetary policy assumes that the central bank formulates policy to minimize the economic consequences of the worst-case specification errors. An alternative approach is for the central bank to build several models and to use these models to develop a policy that produces reasonable, if not optimal, outcomes in all of the models, as described in Levin, Wieland, and Williams (1999, 2003). Although this approach is intuitive and simple to implement, it is not necessarily the most attractive. After all, the approach does not allow the central bank to address any concerns it may have about parameter uncertainty, it does not accommodate the possibility that agents other than the central bank may be concerned about model uncertainty, and it assumes that each of 
the models provides an equally plausible description of the economy. A second alternative is for the central bank to take a Bayesian approach, using Bayesian methods to estimate a range of models and Bayesian model averaging to evaluate competing policies (see Brock, Durlauf, and West (2004) and Batini, Justiniano, Levine, and Pearlman (2005)). The Bayesian approach does not assume that all of the models are equally plausible and it readily accommodates both parameter and model uncertainty, but it still does not easily allow all agents in the model to be concerned about model uncertainty. In contrast, the robust control approach has the advantages that the policymaker need only develop a single model and all agents in the economy can be concerned about model misspecification. Furthermore, the specification errors can reflect both model and parameter uncertainty.

Although model uncertainty - particularly uncertainty concerning exchange rate determination - is of obvious importance for central banks in small open economies (West (2003)), surprisingly few studies have examined the issue. Lees (2004) analyzes a stylized small-open-economy model and finds that robust policies are generally more aggressive in response to shocks and that they imply less interest rate inertia. For his calibration, Lees (2004) concludes that the exchange rate is an important source of specification errors, and that the consequences of these specification errors outweigh the benefits to the central bank of exploiting the exchange rate channel to stabilize the economy. Leitemo and Söderström (2005) study the robustness of simple policy rules to uncertainty about exchange rate determination in a calibrated, stylized, small-open-economy model, concluding that a standard Taylor rule that responds to CPI inflation and the output gap performs well. They also argue that the Taylor rule is more robust to uncertainty about the formation of exchange rate expectations than are rules that respond to exchange rate movements. Leitemo and Söderström (2007) present an analytic treatment of robust control in a small-open-economy model. They show that by guarding against specification errors in either the supply or demand side of the model the central bank raises the volatility of output and the exchange rate, whereas by guarding against specification errors in the exchange rate equation the central bank raises the volatility of inflation. Batini, Justiniano, Levine, and Pearlman (2005) study the effects of Bayesian model uncertainty on monetary policy in an estimated two-country model. Unlike our study, they focus on large open economies and investigate the gains to policy coordination. Finally, Justiniano and Preston (2006) analyze the effects of parameter uncertainty on optimized Taylor-type rules for monetary policy in a structural small-open-economy model estimated on data from Australia, Canada, and New Zealand. Using a Bayesian approach, they find that parameter uncertainty has small effects on the optimized monetary policy rules. However, they only consider parameter uncertainty, whereas we consider more general forms 
of model uncertainty.

The remainder of the paper is organized as follows. We first describe the model and the estimation in Section 2. We then present our robust control algorithm in Section 3. We apply this algorithm to different versions of the model in Section 4 , isolating the effects on robust policymaking of the open-economy policy channels and the open-economy shocks before studying the complete open-economy specification. While we assume in Section 4 that monetary policy is conducted with discretion, we briefly consider the case when policy is conducted with commitment in Section 5 . Finally, we conclude in Section 6 .

\section{The model}

Our model is based on the New Keynesian small open-economy model developed by Monacelli (2005), which, in turn, builds on Galí and Monacelli (2005) and Clarida, Galí, and Gertler (2001). In this model households consume goods produced both domestically and abroad, with staggered price-setting in both the domestic and the import sector. With imported goods subject to price rigidity, and with importers pricing to market, the model can reproduce the incomplete exchange rate pass-through widely found to characterize the behavior of imported goods prices following exchange rate shocks (Campa and Goldberg (2005)). As there is ample evidence supporting incomplete exchange rate pass-through, allowing for sticky imported goods prices seems reasonable, especially since it is likely to be important for the design of monetary policy. A second key feature of the model is that it is not possible to achieve full price stability by setting the output gap to zero. The interest rate policy required to generate a zero output gap destabilizes inflation through its influence on imported goods prices.

The theoretical specification of Monacelli (2005) provides a simple microfounded description of private-sector behavior in an economy where goods prices are sticky. However, the model abstracts from the information and decision lags that can give rise to gradual adjustments and inertial responses to shocks. On the supply side, such inertial responses may be rationalized by firms using rule-of-thumb pricing (Galí and Gertler (1999)) or price indexation (Christiano, Eichenbaum, and Evans (2005)) and, on the demand side, by households having consumption habits (Fuhrer (2000)).

To accommodate the possibility that there may be information and/or decision lags, we adopt the specification of the Monacelli (2005) model estimated by Leitemo (2006), who allows the data to influence the model's lead-lag structure while retaining its steadystate properties. Following Rudebusch (2002), Leitemo (2006) uses expected annual inflation over the coming year to represent the forward-looking component of inflation in the 
Phillips curve, and, following Rotemberg and Woodford (1997), assumes that decisions by households and firms are subject to a one-period implementation lag.

\subsection{Model equations}

Interpreting the model in quarterly terms, the rate of price inflation in the domestic goods sector follow: 1

$$
\pi_{t}^{H}=\mu_{H} \mathrm{E}_{t-1} \bar{\pi}_{t+3}^{H}+\left(1-\mu_{H}\right) \sum_{j=1}^{4} \kappa_{\pi, j} \pi_{t-j}^{H}+\kappa_{x} \mathrm{E}_{t-1} x_{t}+\kappa_{\psi} \mathrm{E}_{t-1} \psi_{t}+\varepsilon_{t}^{H},
$$

where $\pi_{t}^{H} \equiv 4\left(p_{t}^{H}-p_{t-1}^{H}\right)$ is the annualized quarterly rate of inflation for domestically produced goods, $\mathrm{E}_{t-1}$ is the expectation operator conditional on period $t-1$ information, $\bar{\pi}_{t}^{H} \equiv(1 / 4) \sum_{j=0}^{3} \pi_{t-j}^{H}$ is the average four-quarter rate of inflation, $x_{t}$ is the output gap, measured as the percent deviation of domestic output from trend, $\psi_{t}$ is the percent deviation from the law of one price, and $\varepsilon_{t}^{H}$ is a price markup shock in the domestic goods sector.

Equation (1) differs from the standard (closed-economy) New Keynesian Phillips curve through the inclusion of $\psi_{t}$, which enters here because the domestic good is tradeable. This law-of-one-price (LOP) variable is the percent deviation between world market prices (measured in terms of domestic currency) and the domestic price of foreign goods:

$$
\psi_{t} \equiv e_{t}+p_{t}^{*}-p_{t}^{F}
$$

where $e_{t}$ is the nominal exchange rate, $p_{t}^{*}$ is the price of the foreign aggregate good measured in foreign currency, and $p_{t}^{F}$ is the domestic price of the foreign aggregate good.

If import prices were flexible, then the law of one price would hold, implying $p_{t}^{F}=e_{t}+$ $p_{t}^{*}$ and $\psi_{t}=0$. However, in the Monacelli (2005) model importing firms sell the imported goods in a monopolistically competitive market, subject to their demand schedule and a Calvo-style price rigidity. This gives rise to incomplete exchange rate pass-through and implies that imported-goods prices adjust gradually in response to changes in world prices. In our empirical framework, the Phillips curve for imported-goods price inflation is given by

$$
\pi_{t}^{F}=\mu_{F} \mathrm{E}_{t-1} \bar{\pi}_{t+3}^{F}+\left(1-\mu_{F}\right) \sum_{j=1}^{4} \lambda_{\pi, j} \pi_{t-j}^{F}+\lambda_{\psi} \mathrm{E}_{t-1} \psi_{t}+\varepsilon_{t}^{F},
$$

\footnotetext{
${ }^{1}$ All model variables are interpreted as log deviations from steady state.
} 
where $\varepsilon_{t}^{F}$ is a price markup shock in the import sector. Aggregate CPI inflation is then a weighted average of domestic and imported goods inflation:

$$
\pi_{t}^{C}=(1-\gamma) \pi_{t}^{H}+\gamma \pi_{t}^{F}
$$

where $\gamma \in[0,1)$ is the share of imported goods in consumption.

On the demand side, households consume an aggregate domestic good and an aggregate imported good and save by holding domestic and foreign one-period nominal bonds. The household intertemporal consumption choice leads to an Euler equation for the output gap, which in the empirical model is expressed as

$$
\begin{aligned}
x_{t}= & \mu_{x} \mathrm{E}_{t-1} x_{t+1}+\left(1-\mu_{x}\right) \sum_{j=1}^{2} \chi_{x, j} x_{t-j}-\chi_{r}\left[r_{t-1}-\mathrm{E}_{t-1} \bar{\pi}_{t+2}^{H}\right] \\
& +\chi_{\psi} \mathrm{E}_{t-1} \Delta \psi_{t}+\chi_{y *} \mathrm{E}_{t-1} \Delta y_{t}^{*}+\varepsilon_{t}^{x},
\end{aligned}
$$

where $r_{t}$ is the one-period nominal interest rate, $\Delta y_{t}^{*}$ is the growth rate of foreign output, and $\varepsilon_{t}^{x}$ is a productivity disturbance which affects the natural real interest rate. Relative to the closed economy, the LOP variable $\psi_{t}$ enters in equation (5) because households substitute between domestic and foreign goods and because their intertemporal substitution is determined by the real interest rate in terms of CPI inflation, and foreign output growth enters as it affects the natural real interest rate. As the domestic economy is small relative to the foreign economy, foreign output growth is assumed to follow the exogenous autoregressive process

$$
\Delta y_{t}^{*}=\rho_{y *} \Delta y_{t-1}^{*}+\varepsilon_{t}^{y *}
$$

Finally, with perfect capital mobility, the portfolio choice with respect to domestic and foreign bonds implies that the real exchange rate is determined by the risk-adjusted uncovered interest rate parity (UIP) condition

$$
q_{t}=\mathrm{E}_{t} q_{t+1}-\left[r_{t}-(1 / 4) \mathrm{E}_{t} \pi_{t+1}^{C}\right]+r r_{t}^{*}
$$

where $r r_{t}^{*}$ is the foreign one-period real interest rate, assumed to follow the exogenous autoregressive process

$$
r r_{t}^{*}=\sum_{j=1}^{3} \rho_{r r * j} r r_{t-j}^{*}+\varepsilon_{t}^{q} .
$$


Note that exchange rate expectations are formed using period $t$ rather than period $t-1$ information, reflecting the fact that portfolio allocation decisions are not subject to an implementation lag.

\section{$2.2 \quad$ Model estimates}

We estimate the model using GMM applied to quarterly U.K. data over the period 1980:Q1 to 2001:Q4. The data used is described in Appendix A. Following Batini and Haldane (1999), the share of imported goods in the consumer basket, $\gamma$, is set to 0.25 .

Domestic inflation is modeled according to

$$
\begin{aligned}
\pi_{t}^{H}= & \underset{(0.081)}{0.58} \mathrm{E}_{t-1} \bar{\pi}_{t+3}^{H}+\underset{(-)}{0.42}\left[-\underset{(0.16)}{0.39} \pi_{t-1}^{H}+\underset{(0.056)}{0.22} \pi_{t-2}^{H}+\underset{(0.11)}{0.72} \pi_{t-3}^{H}+\underset{(-)}{\left.0.45 \pi_{t-4}^{H}\right]}\right. \\
& +\underset{(0.13)}{0.28 \mathrm{E}_{t-1} x_{t}}+\underset{(0.060)}{0.038 \mathrm{E}_{t-1} \psi_{t}+\varepsilon_{t}^{H}} \\
& \sigma=2.1 \%,
\end{aligned}
$$

where standard errors are reported in parentheses below the estimated coefficients. The null hypothesis that dynamic homogeneity holds cannot be rejected and is imposed, so the coefficients on (leads and lags of) inflation sum to one, ruling out any permanent trade-off between domestic output and domestic inflation. While lags of inflation clearly play an important role in the domestic inflation Phillips curve, it is notable that expected future inflation receives a larger weight than lagged inflation, consistent with the Galí, Gertler, and López-Salido (2001) and Smets (2003) estimates for the euro area, and with the Galí and Gertler (1999) estimates for the U.S., but contrary to Fuhrer (1997) and Rudebusch (2002). The coefficient on the output gap (0.28) indicates relatively rapid price adjustment, but is broadly consistent with Smets (2003) and Batini and Haldane (1999). The slope coefficient on the LOP gap is fairly small, suggesting relatively low substitutability in foreign consumption between U.K. and foreign goods.

Turning to the Phillips curve for imported inflation, the empirical estimates are given by

$$
\begin{aligned}
\pi_{t}^{F}= & \underset{(0.047)}{0.78} \mathrm{E}_{t-1} \bar{\pi}_{t+3}^{F}+\underset{(-)}{0.22}\left[\underset{(0.19)}{1.11} \pi_{t-1}^{F}-\underset{(-)}{0.11 \pi_{t-4}^{F}}\right]+\underset{(0.10)}{0.56 \mathrm{E}_{t-1}} \psi_{t}+\varepsilon_{t}^{F}, \\
& \sigma=5.8 \%
\end{aligned}
$$

Similar to the specification for domestic inflation, the forward-looking inflation component receives a larger weight than the lagged component and dynamic homogeneity cannot be rejected and is imposed. The coefficient on the LOP variable, the driving variable in the 
specification, is large, implying that changes in import costs pass reasonably quickly into the domestic price of imported goods. Together, equations (9) and (10) indicate that domestic prices are subject to greater price rigidity than are imported goods prices. The shock to imported goods inflation also has a somewhat larger standard deviation than the shock to domestic inflation, suggesting that shocks to imported goods prices are likely to be an important source of volatility in the economy, especially because off-setting these shocks forces the central bank to trade-off stabilizing output against stabilizing inflation.

On the demand side, the equation for the output gap is estimated to be

$$
\begin{aligned}
x_{t}= & \underset{(0.039)}{0.53} \mathrm{E}_{t-1} x_{t+1}+\underset{(-)}{0.47}\left[\underset{(0.076)}{1.36} x_{t-1}-\underset{(-)}{0.36 x_{t-2}}\right]-\underset{(0.014)}{0.066}\left[r_{t-1}-\mathrm{E}_{t-1} \bar{\pi}_{t+2}^{H}\right] \\
& +\underset{(0.012)}{0.11} \mathrm{E}_{t-1} \Delta \psi_{t}+\underset{(0.073)}{0.25 \mathrm{E}_{t-1} \Delta y_{t}^{*}+\varepsilon_{t}^{x}} \\
& \sigma=0.41 \% .
\end{aligned}
$$

The output gap responds importantly to the expected future output gap, reflecting standard consumption smoothing behavior, but also to two lags of the output gap. In containing two lags of the output gap, this open-economy IS curve has much in common with closed-economy specifications estimated for the U.S. (see Fuhrer and Moore (1995) and Rudebusch (2002)). Interestingly, the coefficients on the two lags of the gap imply that the gap depends on the level of the lagged gap, consistent with the presence of habit formation, and also on the growth rate of the lagged gap, which can be less easily associated with habit formation. Because equation (11) is estimated using output data rather than consumption data and the model abstracts from investment and capital accumulation, the two lags of the gap may reflect the joint effects of habit formation and investment dynamics (Dennis (2004)). It is worth noting, first, that the coefficient on the ex ante real interest rate is relatively small and that, as a consequence, reasonably large interest rate movements are required to offset demand shocks completely, and, second, that the standard deviation of the output shock is small relative to those for the two Phillips curves.

The coefficients on the two open-economy variables in equation (11) are revealing. First, the coefficient on the LOP variable, at 0.11 , is somewhat larger than its coefficient of 0.038 in the domestic inflation equation. Clearly, deviations from the LOP, which can be exploited for profit through international trade in the domestic good, generate much bigger effects on quantities than prices, further evidence for the rigidity of domestic goods prices. At the same time, the coefficient on $\Delta y_{t}^{*}$ shows that increases in foreign GDP growth generate greater demand for the domestic good, implying, perhaps, that the U.K. is demand-constrained in its ability to export at the world price. 
The "risk-adjusted" real UIP condition is estimated to be

$$
\begin{aligned}
q_{t}= & \mathrm{E}_{t} q_{t+1}-\left[r_{q, t}-(1 / 4) \mathrm{E}_{t} \pi_{t+1}^{C}\right]+r r_{q, t}^{*}, \\
r r_{q, t}^{*}= & \underset{(0.070)}{0.50} r r_{q, t-1}^{*}+\underset{(0.064)}{0.19} r r_{q, t-2}^{*}+\underset{(0.038)}{0.11} r r_{q, t-3}^{*}+\varepsilon_{t}^{q}, \\
& \sigma=3.7 \%,
\end{aligned}
$$

where $r_{q, t}$ and $r r_{q, t}^{*}$ are the domestic and foreign interest rates measured on a quarterly basis. The parameter restrictions associated with UIP were tested and could not be rejected at the usual significance levels. Equation (12) implies that the real exchange rate will "jump" following shocks to ensure that any real interest rate differential is offset by an expected change in the real exchange rate. Because the real exchange rate jumps following shocks, it is likely to be highly volatile, particularly given the large standard deviation of the risk premium shock, and this volatility has important implications for consumer price inflation through imported goods inflation.

Finally, the OECD output growth is modeled using a first-order autoregressive process according to

$$
\begin{aligned}
& \Delta y_{t}^{*}=\underset{(0.066)}{0.51} \Delta y_{t-1}^{*}+\varepsilon_{t}^{y *}, \\
& \sigma=0.50 \% \text {. }
\end{aligned}
$$

Equation (14) reveals that shocks to foreign real GDP growth have a reasonably small standard deviation and that, following such shocks, the effect on real foreign growth dissipates quickly.

Viewed as a system, two features of the model are worth highlighting. First, the model does not allow a permanent trade-off between inflation and output, a knife-edge result that could easily be overturned if either equation (9) or equation (10) were misspecified. Second, it is movements in the LOP variable that are critical for output and inflation, not movements in either the real exchange rate or the terms of trade themselves. As a consequence, the model, as it stands, does not pin down uniquely steady-state values for either the real exchange rate or the terms of trade (the UIP condition has important implications for the change in the real exchange rate, but not for its level). Similarly, equation (2) shows that many combinations of the real exchange rate and the terms of trade are consistent with any given value of the LOP variable. Therefore, depending on how monetary policy is conducted, transitory shocks can have permanent effects on the real exchange rate and the terms of trade. 


\section{The robust control algorithm}

When designing monetary policy, the central bank is assumed to use the estimated model in equations (9)-(14) as its "reference model," that is, the model it believes best describes the data-generating process. However, the central bank fears that the reference model is misspecified, and therefore uses robust control methods to formulate monetary policy. As emphasized by Hansen and Sargent (2007), robust control allows the central bank to design a policy that guards purposefully against specification errors, or distortions, to the reference model that are "small" in the sense that the distorted model lies in a neighborhood "close" to the reference model. In formulating the central bank's robust control problem, we deviate slightly from Hansen and Sargent (2007) and allow the central bank to fear misspecification of both the conditional mean and the conditional volatility of the shock processes; see Dennis, Leitemo, and Söderström (2006) for details.

Our robust control algorithms build on Dennis (2007), who develops numerical methods to solve for the optimal commitment policies and discretionary policies in linear rational expectations models. These algorithms allow the optimization constraints to be written in a structural form as

$$
\mathbf{A}_{0} \mathbf{y}_{t}=\mathbf{A}_{1} \mathbf{y}_{t-1}+\mathbf{A}_{2} \mathrm{E}_{t} \mathbf{y}_{t+1}+\mathbf{A}_{3} \mathbf{u}_{t}+\mathbf{A}_{4} \varepsilon_{t}
$$

where $\mathbf{y}_{t}$ is a vector of endogenous variables, $\mathbf{u}_{t}$ is a vector of policy instrument(s), $\mathbf{v}_{t}$ is a vector of specification errors, $\boldsymbol{\varepsilon}_{t}$ is a vector of innovations, and $\mathbf{A}_{0}, \mathbf{A}_{1}, \mathbf{A}_{2}, \mathbf{A}_{3}$, and $\mathbf{A}_{4}$ are matrices conformable with $\mathbf{y}_{t}, \mathbf{u}_{t}$, and $\varepsilon_{t}$ that contain the parameters of the model. The matrix $\mathbf{A}_{0}$ is assumed to be nonsingular and the elements of $\mathbf{A}_{4}$ are determined to ensure that the shocks are distributed according to $\varepsilon_{t} \sim$ iid $[\mathbf{0}, \mathbf{I}]$. The dating convention is such that any variable that enters $\mathbf{y}_{t-1}$ is predetermined, known by the beginning of period $t$.

Following Hansen and Sargent (2007), the central bank's fear of misspecification is formalized by introducing specification errors to each equation in which there is a shock. To help it devise a robust policy, the central bank assumes that where it desires to minimize a loss function, a fictitious "evil agent" strategically chooses the specification errors to maximize the loss function. With the specification errors cloaked by the shocks, the distorted model is written in the form

$$
\mathbf{A}_{0} \mathbf{y}_{t}=\mathbf{A}_{1} \mathbf{y}_{t-1}+\mathbf{A}_{2} \mathrm{E}_{t} \mathbf{y}_{t+1}+\mathbf{A}_{3} \mathbf{u}_{t}+\mathbf{A}_{4}\left(\mathbf{v}_{t}+\boldsymbol{\varepsilon}_{t}\right)
$$


where the sequence of specification errors, $\left\{\mathbf{v}_{t}\right\}$, is constrained to satisfy

$$
\mathrm{E}_{0} \sum_{t=0}^{\infty} \beta^{t} \mathbf{v}_{t}^{\prime} \mathbf{v}_{t} \leq \eta
$$

where $\eta \in[0, \bar{\eta})$ represents the total "budget" for misspecification. When $\eta$ equals zero, equation (17) implies that $\mathbf{v}_{t}=0$ for all $t$, in which case the distorted model in equation (16) collapses to the reference model.

The central bank's loss function is assumed to take the form

$$
\mathrm{E}_{0} \sum_{t=0}^{\infty} \beta^{t}\left[\mathbf{y}_{t}^{\prime} \mathbf{W} \mathbf{y}_{t}+\mathbf{u}_{t}^{\prime} \mathbf{Q} \mathbf{u}_{t}\right]
$$

where $\mathbf{W}$ and $\mathbf{Q}$ are matrices containing policy weights and are assumed to be symmetric positive-semidefinite and symmetric positive-definite, respectively, and $\beta \in(0,1)$ is the central bank's discount factor.

Hansen and Sargent (2007) show that the problem of minimizing equation (18) with respect to $\mathbf{u}_{t}$ and maximizing with respect to $\mathbf{v}_{t}$ subject to equations (16) and (17) can be replaced with an equivalent multiplier problem in which

$$
\mathrm{E}_{0} \sum_{t=0}^{\infty} \beta^{t}\left[\mathbf{y}_{t}^{\prime} \mathbf{W} \mathbf{y}_{t}+\mathbf{u}_{t}^{\prime} \mathbf{Q} \mathbf{u}_{t}-\theta \mathbf{v}_{t}^{\prime} \mathbf{v}_{t}\right]
$$

is minimized with respect to $\mathbf{u}_{t}$ and maximized with respect to $\mathbf{v}_{t}$, subject to equation 16. The multiplier $\theta \in(\underline{\theta}, \infty]$ is inversely related to the budget for misspecification, $\eta$, and represents the shadow price of a marginal relaxation of the constraint in equation (17).

We focus on the case where monetary policy is set under discretion, so neither the policymaker nor the evil agent can commit to future actions.2 Employing the definitions

$$
\widetilde{\mathbf{Q}} \equiv\left[\begin{array}{cc}
\mathbf{Q} & \mathbf{0} \\
\mathbf{0} & -\boldsymbol{\theta} \mathbf{I}
\end{array}\right], \quad \widetilde{\mathbf{A}}_{3} \equiv\left[\begin{array}{cc}
\mathbf{A}_{3} & \mathbf{A}_{4}
\end{array}\right], \quad \widetilde{\mathbf{u}}_{t} \equiv\left[\begin{array}{c}
\mathbf{u}_{t} \\
\mathbf{v}_{t}
\end{array}\right]
$$

the optimization problem can be written as

$$
\min _{\left\{\mathbf{u}_{t}\right\}_{0}^{\infty}} \max _{\left\{\mathbf{v}_{t}\right\}_{0}^{\infty}} \mathrm{E}_{0} \sum_{t=0}^{\infty} \beta^{t}\left[\mathbf{y}_{t}^{\prime} \mathbf{W} \mathbf{y}_{t}+\widetilde{\mathbf{u}}_{t}^{\prime} \widetilde{\mathbf{Q}} \widetilde{\mathbf{u}}_{t}\right]
$$

\footnotetext{
${ }^{2}$ Appendix $\mathrm{B}$ describes the case of commitment.
} 
subject to

$$
\mathbf{A}_{0} \mathbf{y}_{t}=\mathbf{A}_{1} \mathbf{y}_{t-1}+\mathbf{A}_{2} \mathrm{E}_{t} \mathbf{y}_{t+1}+\widetilde{\mathbf{A}}_{3} \widetilde{\mathbf{u}}_{t}+\mathbf{A}_{4} \varepsilon_{t} .
$$

The problem described by equations (21) and (22) conforms to the class of problems studied by Dennis (2007), where it is shown that the solution to this problem with discretionary policy returns decision rules for the policy instrument $\mathbf{u}_{t}$ and the specification errors $\mathbf{v}_{t}$ that are functions of the predetermined variables $\mathbf{y}_{t-1}$ and the shocks $\varepsilon_{t}$ and take the form 3

$$
\begin{aligned}
\mathbf{y}_{t} & =\mathbf{H} \mathbf{y}_{t-1}+\mathbf{G} \boldsymbol{\varepsilon}_{t}, \\
\widetilde{\mathbf{u}}_{t} & =\mathbf{F}_{1} \mathbf{y}_{t-1}+\mathbf{F}_{2} \boldsymbol{\varepsilon}_{t} .
\end{aligned}
$$

The matrices $\mathbf{H}, \mathbf{G}, \mathbf{F}_{1}$, and $\mathbf{F}_{2}$ that govern the solution are arrived at through an iterative procedure. The first step involves conjecturing values for $\mathbf{H}$ and $\mathbf{F}_{1}$ and using these to solve for the matrix $\mathbf{D}$ and the fix-point $\mathbf{P}$ according to

$$
\begin{aligned}
& \mathbf{D} \equiv \mathbf{A}_{0}-\mathbf{A}_{2} \mathbf{H} \\
& \mathbf{P} \equiv \mathbf{W}+\beta \mathbf{F}_{1}^{\prime} \widetilde{\mathbf{Q}} \mathbf{F}_{1}+\beta \mathbf{H}^{\prime} \mathbf{P} \mathbf{H}
\end{aligned}
$$

Next, the values for $\mathbf{D}$ and $\mathbf{P}$ that solve equations $(25)$ and $(26)$ are used together with the conjectured values for $\mathbf{H}$ and $\mathbf{F}_{1}$ to update $\mathbf{F}_{1}, \mathbf{F}_{2}, \mathbf{H}$, and $\mathbf{G}$ according to

$$
\begin{aligned}
\mathbf{F}_{1} & =-\left(\widetilde{\mathbf{Q}}+\widetilde{\mathbf{A}}_{3}^{\prime} \mathbf{D}^{\prime-1} \mathbf{P} \mathbf{D}^{-1} \widetilde{\mathbf{A}}_{3}\right)^{-1} \widetilde{\mathbf{A}}_{3}^{\prime} \mathbf{D}^{\prime-1} \mathbf{P D}^{-1} \mathbf{A}_{1}, \\
\mathbf{F}_{2} & =-\left(\widetilde{\mathbf{Q}}+\widetilde{\mathbf{A}}_{3}^{\prime} \mathbf{D}^{\prime-1} \mathbf{P} \mathbf{D}^{-1} \widetilde{\mathbf{A}}_{3}\right)^{-1} \widetilde{\mathbf{A}}_{3}^{\prime} \mathbf{D}^{\prime-1} \mathbf{P} \mathbf{D}^{-1} \mathbf{A}_{4}, \\
\mathbf{H} & =\mathbf{D}^{-1}\left(\mathbf{A}_{1}+\widetilde{\mathbf{A}}_{3} \mathbf{F}_{1}\right) \\
\mathbf{G} & =\mathbf{D}^{-1}\left(\mathbf{A}_{4}+\widetilde{\mathbf{A}}_{3} \mathbf{F}_{2}\right) .
\end{aligned}
$$

From equations $25-(30)$, updates of $\mathbf{D}$ and the fix-point $\mathbf{P}$ are generated, which in turn give rise to updated values for $\mathbf{F}_{1}, \mathbf{F}_{2}, \mathbf{H}$, and $\mathbf{G}$. This iterative procedure continues until a fix-point in which $\mathbf{F}_{1}, \mathbf{F}_{2}, \mathbf{H}, \mathbf{G}$, and $\mathbf{P}$ no longer change with successive iterations is obtained.

The solution to this robust control problem yields the central bank's "worst-case" equilibrium, the equilibrium in which the worst-case specification errors are realized, the central bank employs its robust decision rule, and private agents form expectations ac-

\footnotetext{
${ }^{3}$ When the central bank conducts monetary policy with commitment, the solution is, in fact, a function of the complete histories of $\mathbf{y}_{t-1}$ and $\varepsilon_{t}$; see Currie and Levine (1993).
} 
knowledging the central bank's fear of misspecification. Once the worst-case equilibrium has been obtained, it is straightforward to obtain the "approximating" equilibrium, in which the central bank employs its robust decision rule and private agents form expectations acknowledging the central bank's fear of misspecification, but the reference model transpires to be specified correctly.

To construct the approximating equilibrium, we set $\mathbf{v}_{t}=\mathbf{0}$ while retaining the equations for $\mathrm{E}_{t} \mathbf{y}_{t+1}$ and $\mathbf{u}_{t}$ generated by the worst-case equilibrium, and substitute these into equation (16) to solve for $\mathbf{y}_{t}$. This gives

$$
\begin{aligned}
& \mathbf{y}_{t}=\mathbf{A}_{0}^{-1}\left[\left(\mathbf{A}_{1}+\mathbf{A}_{2} \mathbf{H} \mathbf{H}+\mathbf{A}_{3} \mathbf{F}_{1}^{\mathbf{u}}\right) \mathbf{y}_{t-1}+\left(\mathbf{A}_{4}+\mathbf{A}_{2} \mathbf{H G}+\mathbf{A}_{3} \mathbf{F}_{2}^{\mathbf{u}}\right) \boldsymbol{\varepsilon}_{t}\right] \\
& \mathbf{u}_{t}=\mathbf{F}_{1}^{\mathbf{u}} \mathbf{y}_{t-1}+\mathbf{F}_{2}^{\mathbf{u}} \boldsymbol{\varepsilon}_{t}
\end{aligned}
$$

where equation (31) exploits the fact that $\mathbf{A}_{0}$ has full rank.

Following Hansen and Sargent (2007), we determine the set of admissible specification errors by selecting the central bank's preference for robustness to generate a particular "detection error probability," the probability that an econometrician would infer incorrectly whether the approximating equilibrium or the worst-case equilibrium generated the observed data. The intuitive connection between $\theta$ and the probability of making a detection error is that when $\theta$ is small, greater differences between the distorted model and the reference model (more severe misspecifications) can arise, which are more easily detected.

Let model $A$ denote the approximating model and model $B$ denote the worst-case model. Then the probability of making a detection error is given by

$$
p(\theta)=\frac{\operatorname{prob}(A \mid B)+\operatorname{prob}(B \mid A)}{2}
$$

where $\operatorname{prob}(A \mid B)(\operatorname{prob}(B \mid A))$ represents the probability that the econometrician erroneously chooses model $A$ (model $B$ ) when in fact model $B$ (model $A$ ) generated the data. Any sequence of specification errors that satisfies the constraint in equation (17) will be at least as difficult to distinguish from the approximating model as is a sequence that satisfies equation (17) with equality. As such, $p(\theta)$ represents a lower bound on the probability of making a detection error.

To calculate the detection error probability for a given $\theta$, we assume that the selection of one model over another is based on the likelihood ratio principle. Therefore, with $\left\{\mathbf{z}_{t}^{B}\right\}_{1}^{T}$ denoting a finite sequence of economic outcomes generated by the worst-case equilibrium, model $B$, and $L_{A B}$ and $L_{B B}$ denoting the likelihood associated with models $A$ and $B$, respectively, then the econometrician chooses model $A$ over model $B$ if $\log \left(L_{B B} / L_{A B}\right)<0$. 
Generating $M$ independent sequences $\left\{\mathbf{z}_{t}^{B}\right\}_{1}^{T}, \operatorname{prob}(A \mid B)$ can be calculated according to

$$
\operatorname{prob}(A \mid B) \approx \frac{1}{M} \sum_{m=1}^{M} \mathrm{I}\left[\log \left(\frac{L_{B B}^{m}}{L_{A B}^{m}}\right)<0\right]
$$

where $\mathrm{I}\left[\log \left(L_{B B}^{m} / L_{A B}^{m}\right)<0\right]$ is an indicator function that equals one when its argument is satisfied and equals zero otherwise; $\operatorname{prob}(B \mid A)$ is calculated analogously using draws generated from the approximating model. The likelihood function that is generally used to calculate $\operatorname{prob}(A \mid B)$ and $\operatorname{prob}(B \mid A)$ assumes that the innovations are normally distributed.

To calculate detection error probabilities while accounting for the distortions to both the conditional means and the conditional volatilities of the shocks, let

$$
\begin{aligned}
& \mathbf{z}_{t}=\mathbf{H}_{A} \mathbf{z}_{t-1}+\mathbf{G}_{A} \varepsilon_{t}, \\
& \mathbf{z}_{t}=\mathbf{H}_{B} \mathbf{z}_{t-1}+\mathbf{G}_{B} \boldsymbol{\varepsilon}_{t}
\end{aligned}
$$

govern equilibrium outcomes under the approximating equilibrium and the worst-case equilibrium, respectively. When $\mathbf{G}_{A} \neq \mathbf{G}_{B}$, to calculate $p(\theta)$ we must first allow for the stochastic singularity that generally characterizes equilibrium and second account appropriately for the Jacobian of transformation that enters the likelihood function. Using the $\mathrm{QR}$ decomposition, we decompose $\mathbf{G}_{A}$ according to $\mathbf{G}_{A}=\mathbf{Q}_{A} \mathbf{R}_{A}$ and $\mathbf{G}_{B}$ according to $\mathbf{G}_{B}=\mathbf{Q}_{B} \mathbf{R}_{B}$. By construction, $\mathbf{Q}_{A}$ and $\mathbf{Q}_{B}$ are orthogonal matrices $\left(\mathbf{Q}_{A}^{\prime} \mathbf{Q}_{A}=\mathbf{Q}_{B}^{\prime} \mathbf{Q}_{B}=\right.$ I) and $\mathbf{R}_{A}$ and $\mathbf{R}_{B}$ are upper triangular. Let

$$
\widehat{\varepsilon}_{t}^{i \mid j}=\mathbf{R}_{i}^{-1} \mathbf{Q}_{i}^{\prime}\left(\mathbf{z}_{t}^{j}-\mathbf{H}_{i} \mathbf{z}_{t-1}^{j}\right), \quad\{i, j\} \in\{A, B\}
$$

represent the inferred innovations in period $t$ when model $i$ is fitted to data $\left\{\mathbf{z}_{t}^{j}\right\}_{1}^{T}$ that are generated according to model $j$ and let $\widehat{\Sigma}^{i \mid j}$ be the associated estimates of the innovation variance-covariance matrices. Then

$$
\begin{aligned}
& \log \left(\frac{L_{A A}}{L_{B A}}\right)=\log \left|\mathbf{R}_{A}^{-1}\right|-\log \left|\mathbf{R}_{B}^{-1}\right|+\frac{1}{2} \operatorname{tr}\left(\widehat{\boldsymbol{\Sigma}}^{B \mid A}-\widehat{\boldsymbol{\Sigma}}^{A \mid A}\right) \\
& \log \left(\frac{L_{B B}}{L_{A B}}\right)=\log \left|\mathbf{R}_{B}^{-1}\right|-\log \left|\mathbf{R}_{A}^{-1}\right|+\frac{1}{2} \operatorname{tr}\left(\widehat{\boldsymbol{\Sigma}}^{A \mid B}-\widehat{\boldsymbol{\Sigma}}^{B \mid B}\right)
\end{aligned}
$$

where "tr" is the trace operator.

Given equations $(38)$ and $(39)$, equation $(34)$ is used to estimate $\operatorname{prob}(A \mid B)$ and (similarly) $\operatorname{prob}(B \mid A)$, which are needed to construct the detection error probability, as per equation (33). The multiplier, $\theta$, is then determined by selecting a detection error prob- 
ability (or at least its lower bound) and inverting equation (33). Generally this inversion is performed numerically by constructing the mapping between $\theta$ and the detection error probability, for a given sample size.

\section{Robust monetary policy}

In our application, we assume that the central bank's goals are to stabilize four-quarter CPI inflation, $\bar{\pi}_{t}^{C}$, the output gap, $x_{t}$, and the interest rate, $r_{t}$, around their long-run levels, which are normalized to zero, as summarized by the quadratic loss function

$$
\mathrm{E}_{0} \sum_{t=0}^{\infty} \beta^{t}\left[\left(\bar{\pi}_{t}^{C}\right)^{2}+\lambda x_{t}^{2}+\nu r_{t}^{2}\right]
$$

where we set $\beta=0.99, \lambda=1$, and $\nu=0.05$. We focus on the case where monetary policy and the specification errors are chosen with discretion. (Section 5 briefly discusses the commitment case.) We then apply our robust control algorithm to construct the robust monetary policy that guards against distortions to the reference model in equations (9)(14).

To isolate the effects of the transmission channels and shocks that are specific to the open economy, we first analyze a "pseudo-closed" version of the model, eliminating all open-economy elements by setting the open-economy parameters and shocks to zero. This exercise establishes the effects of robust monetary policy in a closed economy, providing a benchmark against which to compare the open-economy results. $4^{4}$ We then proceed by systematically adding open-economy elements to the model. First, we include the openeconomy transmission channels, but continue to exclude the open-economy shocks. Next, we introduce the shocks to imported inflation and foreign output. Finally, we add the shock to the exchange rate (UIP) equation. We incorporate the shocks in this gradual manner to demonstrate and highlight the importance for monetary policy of exchange rate (or UIP) shocks in the open economy.

For each specification, we compare the outcomes of the rational expectations equilibrium (RE), the worst-case equilibrium (WO), and the approximating equilibrium (AP). Throughout, we choose the central bank's preference for robustness so that the detection error probability equals 0.10 , for a sample of 200 observations. This detection error probability allows the distortions to the reference model to be of a reasonable magnitude, but not so large as to make it inconceivable that they would not have been detected previously.

\footnotetext{
${ }^{4}$ The results for this "pseudo-closed" economy are qualitatively very similar to those from the Rudebusch (2002) closed-economy model; see Dennis, Leitemo, and Söderström (2006).
} 


\subsection{Robust monetary policy in a "pseudo-closed" economy}

We first analyze the "pseudo-closed" version of our model. To do this, we shut down all open-economy transmission channels and shocks, leaving the two-equation system

$$
\begin{aligned}
\pi_{t}^{H}= & 0.58 \mathrm{E}_{t-1} \bar{\pi}_{t+3}^{H}+0.42\left[-0.39 \pi_{t-1}^{H}+0.22 \pi_{t-2}^{H}+0.72 \pi_{t-3}^{H}+0.45 \pi_{t-4}^{H}\right] \\
& +0.28 \mathrm{E}_{t-1} x_{t}+\varepsilon_{t}^{H} \\
x_{t}= & 0.53 \mathrm{E}_{t-1} x_{t+1}+0.47\left[1.36 x_{t-1}-0.36 x_{t-2}\right] \\
& -0.066\left[r_{t-1}-\mathrm{E}_{t-1} \bar{\pi}_{t+2}^{H}\right]+\varepsilon_{t}^{x},
\end{aligned}
$$

where $\sigma_{H}=2.1 \%$ and $\sigma_{x}=0.41 \%$. Panel $(a)$ of Tables 13 report the unconditional variances of the key variables, the variances and the cross-correlations for the specification errors, and the distortions to the variance-covariance matrix of the shocks. Figure 1 shows how the model responds to the two shocks.

Consider first the impulse responses in the equilibrium with non-robust policy (RE). The solid lines in Figure 1 show that a positive inflation shock causes the central bank to raise the interest rate, creating a negative output gap and exerting downward pressure on inflation, which returns to target over time. A positive output shock opens up an output gap, which stimulates inflation and causes the central bank to raise the interest rate. With higher interest rates damping demand, the output gap declines and the inflationary pressures diminish, returning the economy to baseline. Looking at the variances of the key variables, because inflation shocks are more volatile than output shocks and pose a more difficult stabilization problem for the central bank, which is forced to lower output to address their inflationary effects, inflation and the interest rate are more volatile than output (see panel $(a)$ of Table 1 ).

Introducing a preference for robustness, the dashed lines representing the worst-case equilibrium (WO) in Figure 1 reveal that the central bank's worst fear is that inflation and output shocks will be larger and have more persistent effects on inflation. Therefore, the robust policy is to raise the interest rate more in response to each shock, which leads to a considerably lower output gap following the inflation shock. Thus, inflation, output, and the interest rate are all more volatile in the worst-case equilibrium than they are in the rational expectations equilibrium.

Panel $(a)$ of Table 2 reveals that the evil agent introduces specification errors primarily to the inflation equation, where shocks are more volatile (so specification errors are more difficult to detect) and pose a more difficult trade-off for the central bank. Indeed, the variance of the specification errors to the inflation equation $\left(v_{t}^{H}\right)$ are two orders of magnitude larger than those to the output equation $\left(v_{t}^{x}\right)$. Table $3(a)$ shows how the evil 
agent in the worst-case equilibrium distorts the variance-covariance matrix of the shocks. Again, the effects of misspecification are considerably larger for inflation shocks than for output shocks, but the evil agent also introduces a small positive covariance between the two shocks.

Finally, Table 1 $(a)$ and the dashed-dotted lines in Figure 1, representing the approximating equilibrium (AP), illustrate that the effect of the more responsive robust policy is to stabilize inflation more than the non-robust policy (RE). However, output and the interest rate are more volatile, leading to a larger overall loss.

These results indicate that a robust central bank in a closed economy worries mainly about specification errors to the inflation equation, and that the cost of insuring against this misspecification comes in the form of greater interest rate and output volatility. Similar conclusions are reached by Dennis, Leitemo, and Söderström (2006) using the closed-economy model estimated by Rudebusch (2002) and by Leitemo and Söderström (2004), who study a stylized closed-economy New Keynesian model.

\subsection{Introducing open-economy channels}

We now introduce the open-economy transmission channels, but retain only the domestic shocks, giving rise to the specification

$$
\begin{aligned}
\pi_{t}^{H}= & 0.58 \mathrm{E}_{t-1} \bar{\pi}_{t+3}^{H}+0.42\left[-0.39 \pi_{t-1}^{H}+0.22 \pi_{t-2}^{H}+0.72 \pi_{t-3}^{H}+0.45 \pi_{t-4}^{H}\right] \\
& +0.28 \mathrm{E}_{t-1} x_{t}+0.038 \mathrm{E}_{t-1} \psi_{t}+\varepsilon_{t}^{H}, \\
\pi_{t}^{F}= & 0.78 \mathrm{E}_{t-1} \bar{\pi}_{t+3}^{F}+0.22\left[1.11 \pi_{t-1}^{F}-0.11 \pi_{t-4}^{F}\right]+0.56 \mathrm{E}_{t-1} \psi_{t}, \\
x_{t}= & 0.53 \mathrm{E}_{t-1} x_{t+1}+0.47\left[1.36 x_{t-1}-0.36 x_{t-2}\right]-0.066\left[r_{t-1}-\mathrm{E}_{t-1} \bar{\pi}_{t+2}^{H}\right] \\
& +0.11 \mathrm{E}_{t-1} \Delta \psi_{t}+\varepsilon_{t}^{x}, \\
q_{t}= & \mathrm{E}_{t} q_{t+1}-\frac{1}{4}\left[r_{t}-\mathrm{E}_{t} \pi_{t+1}\right],
\end{aligned}
$$

where $\sigma_{H}=2.1 \%$ and $\sigma_{x}=0.41 \%$. In this specification, through imported-goods inflation and the real exchange rate, shocks to domestic inflation and output as well as monetary policy interventions have additional effects on the economy.

In the rational expectations equilibrium, Figure 2 shows that the central bank is less responsive to shocks than in the pseudo-closed economy model. This is mainly because domestic shocks have a smaller direct impact on aggregate (CPI) inflation, as importedgoods inflation does not respond contemporaneously to shocks. But to some extent this is also due to the endogenous response of the open-economy variables.

After a shock to domestic inflation, the policy response generates an expected depreci- 
ation of the nominal exchange rate, but also a small initial depreciation, with the nominal exchange rate settling at a higher level than before 5 The exchange rate response leads to an increase in the LOP gap, which then returns to its initial level. These movements in the LOP gap stimulate imported-goods inflation and (to a smaller extent) domestic inflation, while leading to a slightly larger decline in the output gap. As a consequence, the central bank tightens policy less aggressively in response to the shock than it does in the pseudo-closed economy model.

Following an output shock, again the central bank response implies that the nominal exchange rate is expected to depreciate to a higher long-run level, but in this case the initial movement is an appreciation. As a consequence, the LOP gap falls and is expected to increase in the future, leading to slightly lower inflation and a slightly larger output gap than in the pseudo-closed economy model. As with inflation shocks, the central bank responds less aggressively to the output shock.

Table 1 $1(b)$ shows that, as a consequence of these movements in the exchange rate and the LOP gap, inflation and output are more volatile than in the pseudo-closed economy, while the interest rate is considerably less volatile. The net effect is that the loss is slightly higher in value with the open-economy channels than in the pseudo-closed economy.

Turning to the worst-case equilibrium, the effects of misspecification are similar to those in the pseudo-closed economy. The central bank fears that shocks (particularly those to domestic inflation) will have a larger and more persistent effect on domestic and imported-goods inflation. As a consequence, the robust policy is to raise the interest rate more aggressively following adverse inflation shocks, generating a larger decline in output and a larger real exchange rate appreciation. Under the robust monetary policy, inflation is less volatile in the approximating equilibrium than it is in the RE equilibrium, while output and the interest rate are more volatile (Table $1(b)$ ). The specification errors are similar to those in the pseudo-closed economy (Table $2(b)$ ).

To summarize, the presence of the open-economy transmission channels implies that domestic shocks have a smaller direct effect on aggregate (CPI) inflation, but these shocks also affect the economy through the exchange rate and imported inflation. Monetary policy therefore responds slightly less to shocks than it does in the pseudo-closed economy. Relative to the pseudo-closed economy, the main implications for robust monetary policy remain largely unaltered. The central bank fears mainly that shocks will have larger and more persistent effects on domestic inflation than is reflected in the reference model.

\footnotetext{
${ }^{5}$ As the LOP gap returns to its initial level in the long run, the nominal exchange rate will return to the same level as the price of imported goods.
} 


\subsection{An open-economy model without exchange rate shocks}

We now begin to introduce the shocks that are specific to the open economy, starting with the shocks to imported inflation and foreign output growth. We continue, however, to assume that the UIP condition holds perfectly. This leads to the specification

$$
\begin{aligned}
\pi_{t}^{H}= & 0.58 \mathrm{E}_{t-1} \bar{\pi}_{t+3}^{H}+0.42\left[-0.39 \pi_{t-1}^{H}+0.22 \pi_{t-2}^{H}+0.72 \pi_{t-3}^{H}+0.45 \pi_{t-4}^{H}\right] \\
& +0.28 \mathrm{E}_{t-1} x_{t}+0.038 \mathrm{E}_{t-1} \psi_{t}+\varepsilon_{t}^{H} \\
\pi_{t}^{F}= & 0.78 \mathrm{E}_{t-1} \bar{\pi}_{t+3}^{F}+0.22\left[1.11 \pi_{t-1}^{F}-0.11 \pi_{t-4}^{F}\right]+0.56 \mathrm{E}_{t-1} \psi_{t}+\varepsilon_{t}^{F}, \\
x_{t}= & 0.53 \mathrm{E}_{t-1} x_{t+1}+0.47\left[1.36 x_{t-1}-0.36 x_{t-2}\right]-0.066\left[r_{t-1}-\mathrm{E}_{t-1} \bar{\pi}_{t+2}^{H}\right] \\
& +0.11 \mathrm{E}_{t-1} \Delta \psi_{t}+0.25 \mathrm{E}_{t-1} \Delta y_{t}^{*}+\varepsilon_{t}^{x}, \\
q_{t}= & \mathrm{E}_{t} q_{t+1}-\frac{1}{4}\left[r_{t}-\mathrm{E}_{t} \pi_{t+1}\right] \\
\Delta y_{t}^{*}= & 0.51 \Delta y_{t-1}^{*}+\varepsilon_{t}^{y *},
\end{aligned}
$$

where $\sigma_{H}=2.1 \%, \sigma_{F}=5.8 \%, \sigma_{x}=0.41 \%$, and $\sigma_{y *}=0.50 \%$. Note that the shock to imported-goods inflation is more volatile than any of the other shocks, while the standard deviation of the foreign output shock is quite small.

Figure 3 and panel $(c)$ of Tables 13 reveal that the addition of these two openeconomy shocks has surprisingly little impact on the analysis above. Understandably, imported inflation is now more volatile, leading to slightly more volatility in most other variables, but the central bank does not worry much about specification errors to either the imported-goods inflation equation or the foreign output equation. Thus, the introduction of these two shocks leaves the conclusions concerning robust monetary policy largely unaffected. It is unsurprising that the foreign output shock is of little importance, because it has very low variance. As for the imported inflation shock, it has a large variance, but even if imported inflation affects CPI inflation and hence monetary policy directly, it does not have a direct effect on any other variable in the economy, which helps to explain why the central bank has little need to fear that the imported-goods inflation equation is misspecified. 


\subsection{The complete open-economy model}

Finally we add the shock to the UIP condition, leading to the complete model

$$
\begin{aligned}
\pi_{t}^{H}= & 0.58 \mathrm{E}_{t-1} \bar{\pi}_{t+3}^{H}+0.42\left[-0.39 \pi_{t-1}^{H}+0.22 \pi_{t-2}^{H}+0.72 \pi_{t-3}^{H}+0.45 \pi_{t-4}^{H}\right] \\
& +0.28 \mathrm{E}_{t-1} x_{t}+0.038 \mathrm{E}_{t-1} \psi_{t}+\varepsilon_{t}^{H} \\
\pi_{t}^{F}= & 0.78 \mathrm{E}_{t-1} \bar{\pi}_{t+3}^{F}+0.22\left[1.11 \pi_{t-1}^{F}-0.11 \pi_{t-4}^{F}\right]+0.56 \mathrm{E}_{t-1} \psi_{t}+\varepsilon_{t}^{F} \\
x_{t}= & 0.53 \mathrm{E}_{t-1} x_{t+1}+0.47\left[1.36 x_{t-1}-0.36 x_{t-2}\right]-0.066\left[r_{t-1}-\mathrm{E}_{t-1} \bar{\pi}_{t+2}^{H}\right] \\
& +0.11 \mathrm{E}_{t-1} \Delta \psi_{t}+0.25 \mathrm{E}_{t-1} \Delta y_{t}^{*}+\varepsilon_{t}^{x}, \\
q_{t}= & \mathrm{E}_{t} q_{t+1}-\frac{1}{4}\left[r_{t}-\mathrm{E}_{t} \pi_{t+1}\right]+r r_{t}^{*} \\
r r_{t}^{*}= & 0.50 r r_{t-1}^{*}+0.19 r r_{t-2}^{*}+0.11 r r_{t-3}^{*}+\varepsilon_{t}^{q}, \\
\Delta y_{t}^{*}= & 0.51 \Delta y_{t-1}^{*}+\varepsilon_{t}^{y *}
\end{aligned}
$$

where $\sigma_{H}=2.1 \%, \sigma_{F}=5.8 \%, \sigma_{x}=0.41 \%, \sigma_{q}=3.7 \%$, and $\sigma_{y *}=0.50 \%$. Note that the shock to the exchange rate equation has a relatively large variance, and, because the exchange rate directly affects all the other variables in the model (through the LOP gap), this shock has the potential to have important consequences for monetary policy.

This suspicion is confirmed by Figure 4 and Tables 13 , panel $(d)$ : adding the exchange rate shock raises the volatility of all variables, particularly imported-goods inflation and output, whose unconditional variances increase by an order of magnitude 6 Of course, the large effect on imported-goods inflation and output is due to the large coefficients on the LOP gap variable in these equations, while domestic inflation, on the other hand, is largely unaffected. However, the impact on imported-goods inflation and output spills over into monetary policy, and central bank loss in the RE equilibrium also increases by an order of magnitude.

The responses displayed in Figure 4 show that a one-standard-deviation shock $(3.7 \%)$ to the exchange rate generates an increase in CPI inflation of more than $3 \%$, a decline in output of about $2.5 \%$, and a reduction in the interest rate of more than $6 \%$. The looser monetary policy leads to a large nominal exchange rate depreciation and a large increase in the LOP gap.

The scale of the responses to the exchange rate shock make the effects of robustness look small. However, Tables $2(d)$ and $3(d)$ show that this impression is misleading. When the central bank is concerned that the exchange rate equation may be misspecified, it

\footnotetext{
${ }^{6}$ The variances in the complete model are considerably larger than one would expect. Using a standard Taylor rule for monetary policy leads to lower volatility in inflation and, especially, in the interest rate, but higher volatility in the output gap. Nevertheless the variances are still very large in the presence of exchange rate shocks.
} 
becomes much less concerned about specification errors to the other equations in the model and focuses almost exclusively on the possibility that the UIP condition may be misspecified. The central bank's fear that the exchange rate equation may be misspecified is reflected in the conditional volatility of the shocks. Specifically, the central bank worries that exchange rate shocks might be contemporaneously correlated with shocks to other equations.

Finally, note that the effects of robustness in the approximating equilibrium are reasonably small. Output is slightly more volatile than it is in the RE equilibrium, but four-quarter CPI inflation and the interest rate are less volatile. Measured in terms of volatility then, it is not very costly for the central bank to guard against specification errors once exchange rate shocks are taken into account. Underlying this result is the fact that these shocks are very damaging for monetary policy in the RE equilibrium, so departing from the RE policy in favor of the robust policy does not have a large impact on the economy.

\section{Commitment}

Although discretionary policymaking may be more realistic on some levels, since there is no obvious commitment technology, policy commitment may have large effects on the economy, and on the nature of robust policymaking if agents' expectations about the future play an important role in shaping private sector behavior. Recognizing this point, we provide in this section some insight into robust policymaking with commitment. The robust control algorithm for this case are briefly described in Appendix B.

Table 4 reports the unconditional variances and the value of the loss function for the commitment case. Comparing Table 4 $(a)$ with Table $1(a)$, first note that there is a stabilization bias associated with discretionary policymaking: output is less volatile while inflation is more volatile relative to commitment. As a consequence, loss is lower with commitment, although in our specification the gain from commitment is fairly small (loss is about $15 \%$ lower with commitment than with discretion). Similar results are obtained by Dennis and Söderström (2006) using the closed-economy model estimated by Rudebusch (2002). When the central bank seeks robustness, the costs of misspecification are larger under commitment than under discretion, largely because it becomes more costly for the central bank to counter the specification errors. As a consequence, loss in the approximating model is higher under commitment than under discretion.

When the open-economy transmission channels are introduced, the central bank is better able to stabilize the economy, leading to less volatility in all variables. Intuitively, if 
it can commit, then the central bank is able to exploit agents' forward-looking expectations to stabilize the economy. However, as mentioned earlier, the model does not uniquely pin down the steady-state values for either the real exchange rate or the terms of trade. Acting under commitment, the central bank is able to influence expectations to the point where the real exchange rate becomes nonstationary, allowing transitory shocks have permanent effects on the real exchange rate and the terms of trade (but not on the LOP gap) 7 With the real exchange rate absorbing shocks, loss in the rational expectations equilibrium is considerably lower under commitment than under discretion. Nevertheless, the cost of misspecification, and of implementing the robust policy, are still larger (in relative terms) under commitment than under discretion. It is notable that the open-economy channels make distortions to the Phillips curve less costly, since the distortions can be met with movements in the exchange rate as well as movements in the output gap, rather than with movements in the output gap only.

As with discretionary policymaking, adding the shocks to imported inflation and foreign output does not materially change the results, while adding exchange rate shocks is important, although less important than when policy is conducted with discretion. Notably, adding the exchange rate shock increases loss by three times with commitment, but by more than ten times with discretion, so the gain to committing becomes even larger once the exchange rate shock is accounted for. However, interestingly, it is relatively more costly to counteract specification errors and implement a robust policy with commitment than with discretion.

Thus, the main conclusions from our analysis with discretion remain when we assume commitment on the part of the policymaker. The exchange rate equation is still the key concern as a source of specification error, but because the central bank is better able to control the exchange rate when it can commit, misspecification of the domestic inflation equation rises in relative importance. The main difference between commitment and discretion is that the cost of implementing the robust policy is fairly large with commitment but fairly small with discretion. In order to understand this result, note that under commitment the robust central bank minimizes loss, taking into account that the expectations channels can help offset potential specification errors. As a consequence, the deviation between the robust policy and the rational expectations policy can become larger under commitment than under discretion. Through this mechanism, the cost of robustness is (relatively and absolutely) higher when the central bank can commit.

\footnotetext{
${ }^{7}$ This also occurs in Monacelli's (2005) theoretical specification.
} 


\section{Conclusion}

We study the effects of model uncertainty on monetary policy in a small open-economy. We have done this incrementally, moving from a pseudo-closed economy model to an open economy model, adding structure at each step. Along the way we have demonstrated that a robust central bank in a closed economy fears mainly that inflation and output shocks will have larger and more persistent effects on inflation than they do in the reference model. Fearing this persistence, the robust central bank responds aggressively to shocks, giving rise to less inflation volatility but more output volatility than the nonrobust policy.

We have also shown that the open-economy transmission channels per se do not have a large effect on the robust policy. If the only shocks in the economy are to domestic output and inflation, then the conclusions from the closed-economy model remain largely unaltered: the robust central bank fears mainly that the equation for domestic inflation might be misspecified, because distortions to the Phillips curve pose a difficult stabilization problem for the central bank. Introducing shocks to imported-goods inflation and to foreign output does not change our conclusions, because these shocks do not have strong effects on output or consumer price inflation.

Our strongest result concerns shocks to the UIP equation. Once exchange rate shocks are added to the model, all variables in the economy become more volatile, even in the rational expectations equilibrium. Introducing a concern for robustness, we show that monetary policy is particularly sensitive to misspecification of the exchange rate equation and, to a lesser extent, the domestic inflation equation; distortions elsewhere in the economy remain of minor importance. This conclusion has a strong intuition. The UIP condition is estimated imprecisely and, as a consequence, exchange rate shocks are an important source of macroeconomic volatility. Nevertheless, the almost overwhelming dominance of the exchange rate equation as the key concern as a source of misspecification highlights a particularly weak point in open-economy models. A more encouraging finding is that when policy is set with discretion, the cost of insuring against specification errors seems small. 


\section{A Data}

All data are measured at a quarterly frequency and were obtained from either the U.K. national accounts, the IMF, or the OECD.

Domestic inflation is constructed as $\pi_{t}^{H} \equiv 4\left(p_{t}^{H}-p_{t-1}^{H}\right)$, where $p_{t}^{H}$ is the GDP price deflator, and imported-goods inflation is measured using the price of imported goods according to $\pi_{t}^{F} \equiv 4\left(p_{t}^{F}-p_{t-1}^{F}\right)$. The quarterly rate of consumer price inflation, $\pi_{t}^{C}$, is then given by equation (4). The output gap, $x_{t}$, is calculated as the deviation of log real GDP from an HP-filtered trend, using a smoothing parameter of 1,600.

The effective real exchange rate, $q_{t}$, is measured by deflating the effective tradeweighted nominal exchange rate by the corresponding relative CPI indices as $q_{t} \equiv e_{t}+$ $p_{t}^{*}-p_{t}^{C}$, and the LOP gap is generated from equation (2) as

$$
\begin{aligned}
\psi_{t} & \equiv e_{t}+p_{t}^{*}-p_{t}^{F} \\
& =q_{t}-(1-\gamma) s_{t}
\end{aligned}
$$

using the detrended effective real exchange rate and the terms of trade.

The domestic interest rate, $r_{t}$, is the 3 -month U.K. T-bill rate, expressed at an annual rate, and the foreign real interest rate, $r r_{t}^{*}$, is the 3-month OECD average, also expressed at an annual rate. Finally, foreign output, $y_{t}^{*}$, is approximated by the OECD output gap, with $\Delta y_{t}^{*}$ representing the quarterly growth rate of foreign GDP. 


\section{B The robust control algorithm with commitment}

Building on Dennis (2007), to solve the robust control problem with commitment the optimization problem is formulated using the Lagrangian

$$
L=\mathrm{E}_{0} \sum_{t=0}^{\infty} \beta^{t}\left[\mathbf{y}_{t}^{\prime} \mathbf{W} \mathbf{y}_{t}+\widetilde{\mathbf{u}}_{t}^{\prime} \widetilde{\mathbf{Q}} \widetilde{\mathbf{u}}_{t}+2 \boldsymbol{\lambda}_{t}^{\prime}\left(\mathbf{A}_{0} \mathbf{y}_{t}-\mathbf{A}_{1} \mathbf{y}_{t-1}-\mathbf{A}_{2} \mathbf{y}_{t+1}-\widetilde{\mathbf{A}}_{3} \widetilde{\mathbf{u}}_{t}-\rho_{t}\right)\right],
$$

where $\rho_{t} \equiv \mathbf{A}_{4} \varepsilon_{t}-\mathbf{A}_{2}\left(\mathbf{y}_{t+1}-\mathrm{E}_{t} \mathbf{y}_{t+1}\right)$. The first-order conditions with respect to $\widetilde{\mathbf{u}}_{t}, \boldsymbol{\lambda}_{t}$, and $\mathbf{y}_{t}$, respectively, can be written as

$$
\begin{aligned}
\frac{\partial L}{\partial \widetilde{\mathbf{u}}_{t}} & =\widetilde{\mathbf{Q}} \widetilde{\mathbf{u}}_{t}-\widetilde{\mathbf{A}}_{3}^{\prime} \boldsymbol{\lambda}_{t}=\mathbf{0}, t \geq t_{0}, \\
\frac{\partial L}{\partial \boldsymbol{\lambda}_{t}} & =\mathbf{A}_{0} \mathbf{y}_{t}-\mathbf{A}_{1} \mathbf{y}_{t-1}-\mathbf{A}_{2} \mathrm{E}_{t} \mathbf{y}_{t+1}-\widetilde{\mathbf{A}}_{3} \widetilde{\mathbf{u}}_{t}-\mathbf{A}_{4} \varepsilon_{t}=\mathbf{0}, t \geq t_{0}, \\
\frac{\partial L}{\partial \mathbf{y}_{t}} & =\mathbf{W} \mathbf{y}_{t}+\mathbf{A}_{0}^{\prime} \boldsymbol{\lambda}_{t}-\beta^{-1} \mathbf{A}_{2}^{\prime} \boldsymbol{\lambda}_{t-1}-\beta \mathbf{A}_{1}^{\prime} \mathrm{E}_{t} \boldsymbol{\lambda}_{t+1}=\mathbf{0}, t \geq t_{0},
\end{aligned}
$$

with the initial condition that $\boldsymbol{\lambda}_{t-1}=\mathbf{0}$. Equations $(\mathrm{B} 2)-(\mathrm{B} 4)$ describe a standard system of expectational equations, and the solution can be written as

$$
\begin{aligned}
{\left[\begin{array}{c}
\boldsymbol{\lambda}_{t} \\
\mathbf{y}_{t}
\end{array}\right] } & =\left[\begin{array}{ll}
\mathbf{H}_{\boldsymbol{\lambda} \boldsymbol{\lambda}} & \mathbf{H}_{\boldsymbol{\lambda} \mathbf{y}} \\
\mathbf{H}_{\mathbf{y} \boldsymbol{\lambda}} & \mathbf{H}_{\mathbf{y y}}
\end{array}\right]\left[\begin{array}{l}
\boldsymbol{\lambda}_{t-1} \\
\mathbf{y}_{t-1}
\end{array}\right]+\left[\begin{array}{l}
\mathbf{G}_{\boldsymbol{\lambda} \varepsilon} \\
\mathbf{G}_{\mathbf{y} \varepsilon}
\end{array}\right] \boldsymbol{\varepsilon}_{t}, \\
\widetilde{\mathbf{u}}_{t} & =\left[\begin{array}{ll}
\mathbf{F}_{\boldsymbol{\lambda}} & \mathbf{F}_{\mathbf{y}}
\end{array}\right]\left[\begin{array}{l}
\boldsymbol{\lambda}_{t-1} \\
\mathbf{y}_{t-1}
\end{array}\right]+\mathbf{F}_{\varepsilon} \varepsilon_{t} .
\end{aligned}
$$

Equations (B5) and (B6) describe how the economy behaves in the worst-case equilibrium. The approximating equilibrium is then given by

$$
\begin{aligned}
\boldsymbol{\lambda}_{t}= & \mathbf{H}_{\boldsymbol{\lambda} \boldsymbol{\lambda}} \boldsymbol{\lambda}_{t-1}+\mathbf{H}_{\boldsymbol{\lambda} \mathbf{y}} \mathbf{y}_{t-1}+\mathbf{G}_{\boldsymbol{\lambda} \varepsilon} \varepsilon_{t} \\
\mathbf{u}_{t}= & \mathbf{F}_{\boldsymbol{\lambda}}^{\mathbf{u}} \boldsymbol{\lambda}_{t-1}+\mathbf{F}_{\mathbf{y}}^{\mathbf{u}} \mathbf{y}_{t-1}+\mathbf{F}_{\varepsilon}^{\mathbf{u}} \varepsilon_{t} \\
\mathbf{y}_{t}= & \mathbf{A}_{0}^{-1}\left[\mathbf{A}_{1}+\mathbf{A}_{2}\left(\mathbf{H}_{\mathbf{y} \boldsymbol{\lambda}} \mathbf{H}_{\boldsymbol{\lambda} \mathbf{y}}+\mathbf{H}_{\mathbf{y y}} \mathbf{H}_{\mathbf{y y}}\right)+\mathbf{A}_{3} \mathbf{F}_{\mathbf{y}}^{\mathbf{u}}\right] \mathbf{y}_{t-1} \\
& +\mathbf{A}_{0}^{-1}\left[\mathbf{A}_{2}\left(\mathbf{H}_{\mathbf{y} \boldsymbol{\lambda}} \mathbf{H}_{\boldsymbol{\lambda} \boldsymbol{\lambda}}+\mathbf{H}_{\mathbf{y} \mathbf{y}} \mathbf{H}_{\mathbf{y} \boldsymbol{\lambda}}\right)+\mathbf{A}_{3} \mathbf{F}_{\boldsymbol{\lambda}}^{\mathbf{u}}\right] \boldsymbol{\lambda}_{t-1} \\
& +\mathbf{A}_{0}^{-1}\left[\mathbf{A}_{4}+\mathbf{A}_{2}\left(\mathbf{H}_{\mathbf{y} \boldsymbol{\lambda}} \mathbf{G}_{\boldsymbol{\lambda} \boldsymbol{\varepsilon}}+\mathbf{H}_{\mathbf{y} \mathbf{y}} \mathbf{G}_{\mathbf{y} \boldsymbol{\varepsilon}}\right)+\mathbf{A}_{3} \mathbf{F}_{\varepsilon}^{\mathbf{u}}\right] \varepsilon_{t} .
\end{aligned}
$$




\section{References}

Batini, Nicoletta and Andrew G. Haldane (1999), "Forward-looking rules for monetary policy," in Taylor, John. B. (ed.), Monetary Policy Rules, The University of Chicago Press.

Batini, Nicoletta, Alejandro Justiniano, Paul Levine, and Joseph Pearlman (2005), "Model uncertainty and the gains from coordinating monetary rules," Manuscript, International Monetary Fund.

Brock, William A., Steven N. Durlauf, and Kenneth D. West (2004), "Model uncertainty and policy evaluation: Some theory and empirics," Working Paper No. 10916, National Bureau of Economic Research.

Calvo, Guillermo A. (1983), "Staggered prices in a utility-maximizing framework," Journal of Monetary Economics 12 (3), 383-398.

Campa, José Manuel and Linda S. Goldberg (2005), "Exchange rate pass-through into import prices," Review of Economics and Statistics 87 (4), 679-690.

Christiano, Lawrence J., Martin Eichenbaum, and Charles L. Evans (2005), "Nominal rigidities and the dynamic effects of a shock to monetary policy," Journal of Political Economy 113 (1), 1-45.

Clarida, Richard, Jordi Galí, and Mark Gertler (1999), "The science of monetary policy: A New Keynesian perspective," Journal of Economic Literature 37 (4), 1661-1707.

Clarida, Richard, Jordi Galí, and Mark Gertler (2001), "Optimal monetary policy in open versus closed economies: An integrated approach," American Economic Review Papers and Proceedings 91 (2), 248-252.

Currie, David and Paul Levine (1993), Rules, Reputation and Macroeconomic Policy Coordination, Cambridge University Press.

Dennis, Richard (2004), "Specifying and estimating New Keynesian models with instrument rules and optimal monetary policies," Working Paper No. 2004-17, Federal Reserve Bank of San Francisco.

Dennis, Richard (2007), "Optimal policy in rational expectations models: New solution algorithms," Macroeconomic Dynamics 11 (1), 31-55.

Dennis, Richard, Kai Leitemo, and Ulf Söderström (2006), "Methods for robust control," Working Paper No. 2006-10, Federal Reserve Bank of San Francisco.

Dennis, Richard and Ulf Söderström (2006), "How important is commitment for monetary policy?" Journal of Money, Credit, and Banking 38 (4), 847-872.

Fuhrer, Jeffrey C. (1997), "The (un)importance of forward-looking behavior in price specifications," Journal of Money, Credit, and Banking 29 (3), 338-350. 
Fuhrer, Jeffrey C. (2000), "Habit formation in consumption and its implications for monetary-policy models," American Economic Review 90 (3), 367-90.

Fuhrer, Jeffrey C. and George Moore (1995), "Monetary policy trade-offs and the correlation between nominal interest rates and real output," American Economic Review 85 (1), 219-239.

Galí, Jordi and Mark Gertler (1999), "Inflation dynamics: A structural econometric analysis," Journal of Monetary Economics 44 (2), 195-222.

Galí, Jordi, Mark Gertler, and David López-Salido (2001), "European inflation dynamics," European Economic Review 45 (7), 1237-1270.

Galí, Jordi and Tommaso Monacelli, "Monetary policy and exchange rate volatility in a small open economy," Review of Economic Studies 72 (3), 702-734.

Goodfriend, Marvin and Robert G. King (1997), "The new neoclassical synthesis and the role of monetary policy," in Bernanke, Ben S. and Julio J. Rotemberg (eds.), NBER Macroeconomics Annual, MIT Press, Cambridge, MA.

Hansen, Lars Peter and Thomas J. Sargent (2007), Robustness, Book manuscript, University of Chicago and New York University. Forthcoming, Princeton University Press.

Justiniano, Alejandro and Bruce Preston (2006), "Monetary policy and uncertainty in an empirical small open economy model," Manuscript, Columbia University.

Lees, Kirdan (2004), "What do robust monetary policies look like for open economy inflation targeters?," Manuscript, Reserve Bank of New Zealand.

Leitemo, Kai (2006), "Targeting inflation by forecast feedback rules in small open economies," Journal of Economic Dynamics and Control 30 (3), 393-413.

Leitemo, Kai and Ulf Söderström (2004), "Robust monetary policy in the New-Keynesian framework," Discussion Paper No. 4805, Centre for Economic Policy Research. Forthcoming, Macroeconomic Dynamics.

Leitemo, Kai and Ulf Söderström (2005), "Simple monetary policy rules and exchange rate uncertainty," Journal of International Money and Finance 24 (3), 481-507.

Leitemo, Kai and Ulf Söderström (2007), "Robust monetary policy in a small open economy," Manuscript, Norwegian School of Management and IGIER, Bocconi University.

Levin, Andrew T., Volker Wieland, and John C. Williams (1999), "Robustness of simple monetary policy rules under model uncertainty," in Taylor, John B. (ed.), Monetary Policy Rules, The University of Chicago Press. 
Levin, Andrew T., Volker Wieland, and John C. Williams (2003), "The performance of forecast-based monetary policy rules under model uncertainty," American Economic Review 93 (3), 622-645.

McCallum, Bennett T. and Edward Nelson (1999), "Nominal income targeting in an open-economy optimizing model," Journal of Monetary Economics 43 (3), 553-578.

Monacelli, Tommaso (2005), "Monetary policy in a low pass-through environment," Journal of Money, Credit, and Banking 37 (6), 1047-1066.

Rotemberg, Julio J. and Michael Woodford (1997), "An optimization-based econometric framework for the evaluation of monetary policy," in Bernanke, Ben S. and Julio J. Rotemberg (eds.), NBER Macroeconomics Annual, MIT Press, Cambridge, MA.

Rudebusch, Glenn D. (2002), "Assessing nominal income rules for monetary policy with model and data uncertainty," Economic Journal 112 (479), 1-31.

Smets, Frank (2003), "Maintaining price stability: How long is the medium term," Journal of Monetary Economics 50 (6), 1293-1309.

West, Kenneth D. (2003), "Monetary policy and the volatility of real exchange rates in New Zealand," Discussion Paper No. 2003/09, Reserve Bank of New Zealand.

Woodford, Michael (2003), Interest and Prices: Foundations of a Theory of Monetary Policy, Princeton University Press. 
Table 1: Unconditional variances and loss

\begin{tabular}{|c|c|c|c|c|c|c|c|c|c|}
\hline & \multicolumn{8}{|c|}{ Variance in } & \multirow[t]{2}{*}{ Loss } \\
\hline & $\bar{\pi}_{t}^{C}$ & $\pi_{t}^{H}$ & $\pi_{t}^{F}$ & $\pi_{t}^{C}$ & $x_{t}$ & $\Delta q_{t}$ & $\psi_{t}$ & $r_{t}$ & \\
\hline \multicolumn{10}{|c|}{ (a) Closed-economy version } \\
\hline $\mathrm{RE}$ & 2.39 & 5.85 & & & 0.64 & & & 3.09 & 3.03 \\
\hline WO & 4.46 & 8.24 & & & 4.02 & & & 7.28 & 8.19 \\
\hline $\mathrm{AP}$ & 2.02 & 5.46 & & & 2.19 & & & 4.80 & 4.25 \\
\hline \multicolumn{10}{|c|}{ (b) Open-economy model with only domestic shocks } \\
\hline $\mathrm{RE}$ & 2.49 & 6.05 & 2.93 & 4.26 & 0.69 & 0.12 & 0.27 & 2.57 & 3.11 \\
\hline WO & 4.87 & 8.83 & 5.02 & 6.83 & 4.19 & 0.53 & 0.12 & 7.18 & 8.59 \\
\hline $\mathrm{AP}$ & 2.06 & 5.66 & 2.24 & 3.84 & 2.14 & 0.55 & 0.09 & 4.49 & 4.20 \\
\hline \multicolumn{10}{|c|}{ (c) Open-economy model without exchange rate shock } \\
\hline $\mathrm{RE}$ & 2.99 & 6.15 & 42.79 & 6.67 & 0.97 & 1.36 & 9.93 & 4.72 & 3.97 \\
\hline WO & 5.46 & 8.98 & 46.10 & 9.39 & 4.36 & 1.92 & 10.35 & 9.57 & 9.42 \\
\hline $\mathrm{AP}$ & 2.56 & 5.74 & 42.39 & 6.27 & 2.36 & 1.95 & 10.01 & 6.61 & 4.98 \\
\hline \multicolumn{10}{|c|}{ (d) Open-economy model with all shocks } \\
\hline $\mathrm{RE}$ & 17.28 & 8.30 & 509.27 & 31.82 & 20.34 & 680.40 & 948.70 & 150.45 & 43.13 \\
\hline WO & 21.85 & 9.25 & 622.81 & 39.02 & 29.41 & 861.77 & 1218.11 & 176.04 & 57.31 \\
\hline $\mathrm{AP}$ & 16.28 & 8.14 & 531.54 & 33.28 & 22.50 & 879.91 & 1015.31 & 138.10 & 43.80 \\
\hline
\end{tabular}

Note: The table shows the unconditional variances of key variables and expected loss in four versions of the open-economy model when monetary policy and specification errors are set with discretion. The loss function is given by equation (40) with $\beta=0.99, \lambda=1$, and $\nu=0.05$; the preference for robustness is chosen to produce a detection error probability of 0.10 . 
Table 2: Unconditional variances and correlations between specification errors

\begin{tabular}{|c|c|c|c|c|c|}
\hline & \multicolumn{5}{|c|}{ Specification error } \\
\hline & $v_{t}^{H}$ & $v_{t}^{F}$ & $v_{t}^{x}$ & $v_{t}^{q}$ & $v_{t}^{y *}$ \\
\hline \multicolumn{6}{|c|}{ (a) Closed-economy version } \\
\hline$v_{t}^{H}$ & 0.046 & \multicolumn{3}{|c|}{-0.671} & \\
\hline$v_{t}^{x}$ & -0.671 & \multicolumn{3}{|c|}{$1.261 \times 10^{-4}$} & \\
\hline \multicolumn{6}{|c|}{ (b) Open-economy model with only domestic shocks } \\
\hline$v_{t}^{H}$ & 0.048 & \multicolumn{3}{|c|}{-0.502} & \\
\hline$v_{t}^{x}$ & -0.502 & \multicolumn{3}{|c|}{$9.242 \times 10^{-5}$} & \\
\hline \multicolumn{6}{|c|}{ (c) Open-economy model without exchange rate shock } \\
\hline$v_{t}^{H}$ & 0.048 & 0.524 & -0.383 & & 0.925 \\
\hline$v_{t}^{F}$ & 0.524 & $2.846 \times 10^{-4}$ & -0.044 & & 0.670 \\
\hline$v_{t}^{x}$ & -0.383 & -0.044 & $1.300 \times 10^{-4}$ & & -0.056 \\
\hline$v_{t}^{y *}$ & 0.925 & 0.670 & -0.056 & & $1.431 \times 10^{-4}$ \\
\hline \multicolumn{6}{|c|}{ (d) Open-economy model with all shocks } \\
\hline$v_{t}^{H}$ & $1.699 \times 10^{-3}$ & -0.130 & -0.119 & 0.526 & -0.048 \\
\hline$v_{t}^{F}$ & -0.130 & $1.076 \times 10^{-4}$ & 0.071 & -0.505 & 0.467 \\
\hline$v_{t}^{x}$ & -0.119 & 0.071 & $1.289 \times 10^{-4}$ & -0.797 & 0.896 \\
\hline$v_{t}^{q}$ & 0.526 & -0.505 & -0.797 & 0.026 & -0.873 \\
\hline$v_{t}^{y *}$ & -0.048 & 0.467 & 0.896 & -0.873 & $5.641 \times 10^{-5}$ \\
\hline
\end{tabular}

Note: The table shows the unconditional variances (along the diagonal) and cross-correlations (off the diagonal) of worst-case specification errors in four versions of the open-economy model when monetary policy and specification errors are set with discretion. The preference for robustness is chosen to produce a detection error probability of 0.10 . 
Table 3: Distortions to conditional variances and covariances

\begin{tabular}{|c|c|c|c|c|c|}
\hline & $\varepsilon_{t}^{H}$ & $\varepsilon_{t}^{F}$ & $\overline{\varepsilon_{t}^{x}}$ & $\varepsilon_{t}^{q}$ & $\varepsilon_{t}^{y *}$ \\
\hline \multicolumn{6}{|c|}{ Structural variances } \\
\hline & 4.41 & 33.64 & 0.1681 & 13.69 & 0.25 \\
\hline \multicolumn{6}{|c|}{ (a) Closed-economy version } \\
\hline$\varepsilon_{t}^{H}$ & 5.121 & & $5.325 \times 10^{-3}$ & & \\
\hline$\varepsilon_{t}^{x}$ & $5.325 \times 10^{-3}$ & & 0.170 & & \\
\hline \multicolumn{6}{|c|}{ (b) Open-economy model with only domestic shocks } \\
\hline$\varepsilon_{t}^{H}$ & 5.061 & & $6.681 \times 10^{-3}$ & & \\
\hline$\varepsilon_{t}^{x}$ & $6.681 \times 10^{-3}$ & & 0.170 & & \\
\hline \multicolumn{6}{|c|}{ (c) Open-economy model without exchange rate shock } \\
\hline$\varepsilon_{t}^{H}$ & 5.048 & 0.034 & $6.609 \times 10^{-3}$ & & 0.010 \\
\hline$\varepsilon_{t}^{F}$ & 0.034 & 34.340 & $5.679 \times 10^{-3}$ & & $9.984 \times 10^{-3}$ \\
\hline$\varepsilon_{t}^{x}$ & $6.609 \times 10^{-3}$ & $5.679 \times 10^{-3}$ & 0.170 & & $6.331 \times 10^{-4}$ \\
\hline$\varepsilon_{t}^{y *}$ & 0.010 & $9.984 \times 10^{-3}$ & $6.331 \times 10^{-4}$ & & 0.251 \\
\hline \multicolumn{6}{|c|}{ (d) Open-economy model with all shocks } \\
\hline$\varepsilon_{t}^{H}$ & 4.490 & $-1.313 \times 10^{-3}$ & $4.730 \times 10^{-4}$ & 0.181 & $5.579 \times 10^{-4}$ \\
\hline$\varepsilon_{t}^{F}$ & $-1.313 \times 10^{-3}$ & 33.781 & $1.426 \times 10^{-3}$ & -0.347 & $2.590 \times 10^{-3}$ \\
\hline$\varepsilon_{t}^{x}$ & $4.730 \times 10^{-4}$ & $1.426 \times 10^{-3}$ & 0.168 & $-9.419 \times 10^{-3}$ & $1.065 \times 10^{-4}$ \\
\hline$\varepsilon_{t}^{q}$ & 0.181 & -0.347 & $-9.419 \times 10^{-3}$ & 16.705 & -0.017 \\
\hline$\varepsilon_{t}^{y *}$ & $5.579 \times 10^{-4}$ & $2.590 \times 10^{-3}$ & $1.065 \times 10^{-4}$ & -0.017 & 0.250 \\
\hline
\end{tabular}

Note: The table shows the impact of worst-case specification errors on the variance-covariance matrix of shocks in four versions of the open-economy model when monetary policy and specification errors are set with discretion. The preference for robustness is chosen to produce a detection error probability of 0.10 . 
Table 4: Unconditional variances and loss with commitment

\begin{tabular}{|c|c|c|c|c|c|c|c|c|c|}
\hline & \multicolumn{8}{|c|}{ Variance in } & \multirow[t]{2}{*}{ Loss } \\
\hline & $\bar{\pi}_{t}^{C}$ & $\pi_{t}^{H}$ & $\pi_{t}^{F}$ & $\pi_{t}^{C}$ & $x_{t}$ & $\Delta q_{t}$ & $\psi_{t}$ & $r_{t}$ & \\
\hline \multicolumn{10}{|c|}{ (a) Closed-economy version } \\
\hline $\mathrm{RE}$ & 1.52 & 5.08 & & & 1.03 & & & 1.49 & 2.52 \\
\hline WO & 2.52 & 6.19 & & & 5.53 & & & 3.16 & 7.70 \\
\hline $\mathrm{AP}$ & 1.50 & 5.01 & & & 3.34 & & & 2.06 & 4.71 \\
\hline \multicolumn{10}{|c|}{ (b) Open-economy model with only domestic shocks } \\
\hline $\mathrm{RE}$ & 0.39 & 5.30 & 11.34 & 3.25 & 0.78 & 10.66 & 14.24 & 5.33 & 1.37 \\
\hline WO & 0.73 & 6.20 & 22.81 & 4.14 & 4.98 & 19.43 & 27.87 & 10.19 & 5.71 \\
\hline $\mathrm{AP}$ & 0.48 & 5.25 & 24.24 & 3.85 & 3.26 & 20.14 & 27.78 & 8.05 & 3.87 \\
\hline \multicolumn{10}{|c|}{ (c) Open-economy model without exchange rate shock } \\
\hline $\mathrm{RE}$ & 0.91 & 5.31 & 47.74 & 5.54 & 0.82 & 10.78 & 18.22 & 6.41 & 1.96 \\
\hline WO & 1.30 & 6.19 & 59.42 & 6.47 & 5.03 & 18.52 & 29.28 & 11.34 & 6.37 \\
\hline $\mathrm{AP}$ & 1.04 & 5.28 & 59.93 & 6.12 & 3.33 & 19.19 & 29.58 & 9.31 & 4.53 \\
\hline \multicolumn{10}{|c|}{ (d) Open-economy model with all shocks } \\
\hline $\mathrm{RE}$ & 2.02 & 10.55 & 156.94 & 7.08 & 3.06 & 120.06 & 116.48 & 24.13 & 5.93 \\
\hline WO & 4.25 & 12.31 & 256.91 & 10.23 & 8.40 & 185.20 & 194.77 & 37.27 & 13.42 \\
\hline $\mathrm{AP}$ & 3.16 & 11.06 & 213.84 & 9.09 & 6.46 & 184.69 & 180.42 & 32.41 & 10.51 \\
\hline
\end{tabular}

Note: The table shows the unconditional variances of key variables and expected loss in four versions of the open-economy model when monetary policy and specification errors are set with commitment. The loss function is given by equation (40) with $\beta=0.99, \lambda=1$, and $\nu=0.05$; the preference for robustness is chosen so as to produce a detection error probability of 0.10 . 
Figure 1: Impulse responses in closed-economy version

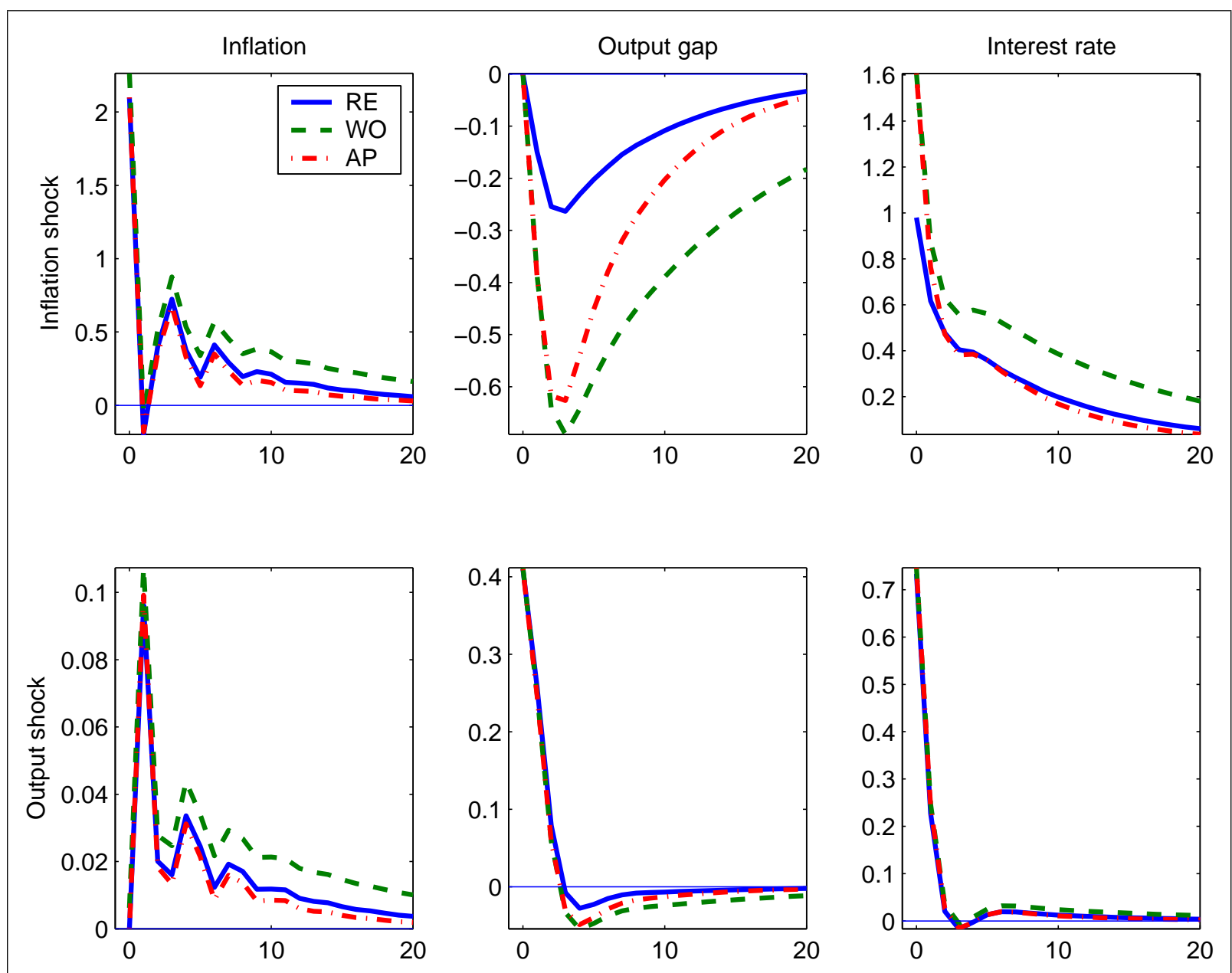

Note: The figure shows impulse responses of key variables to shocks (of one standard deviation) in the closed-economy version of the model when monetary policy and specification errors are set with discretion. The preference for robustness is chosen to produce a detection error probability of 0.10 . 
Figure 2: Impulse responses in open-economy model with only domestic shocks

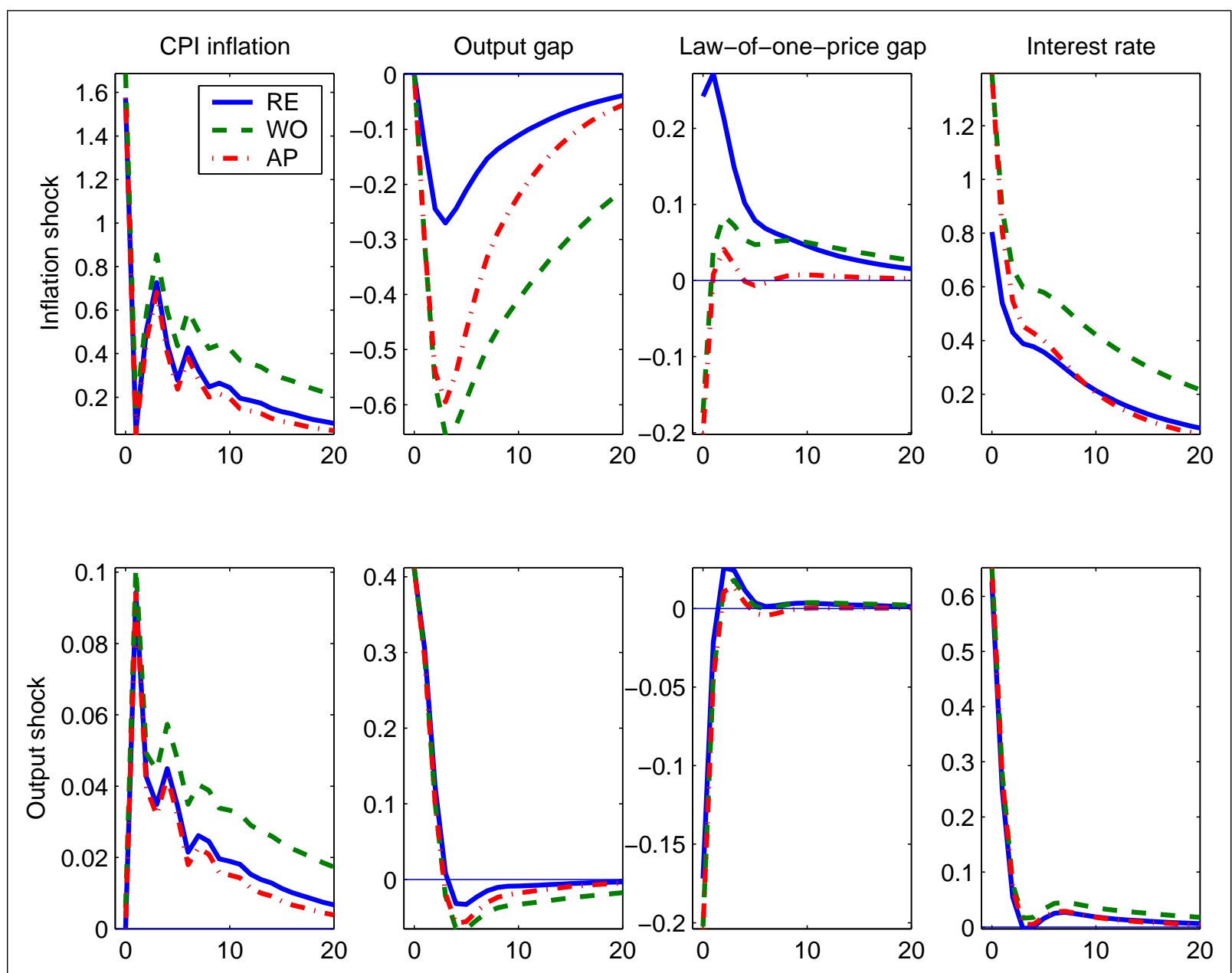

Note: The figure shows impulse responses of key variables to shocks (of one standard deviation) in the open-economy model with only domestic shocks when monetary policy and specification errors are set with discretion. The preference for robustness is chosen to produce a detection error probability of 0.10. 
Figure 3: Impulse responses in open-economy model without exchange rate shocks

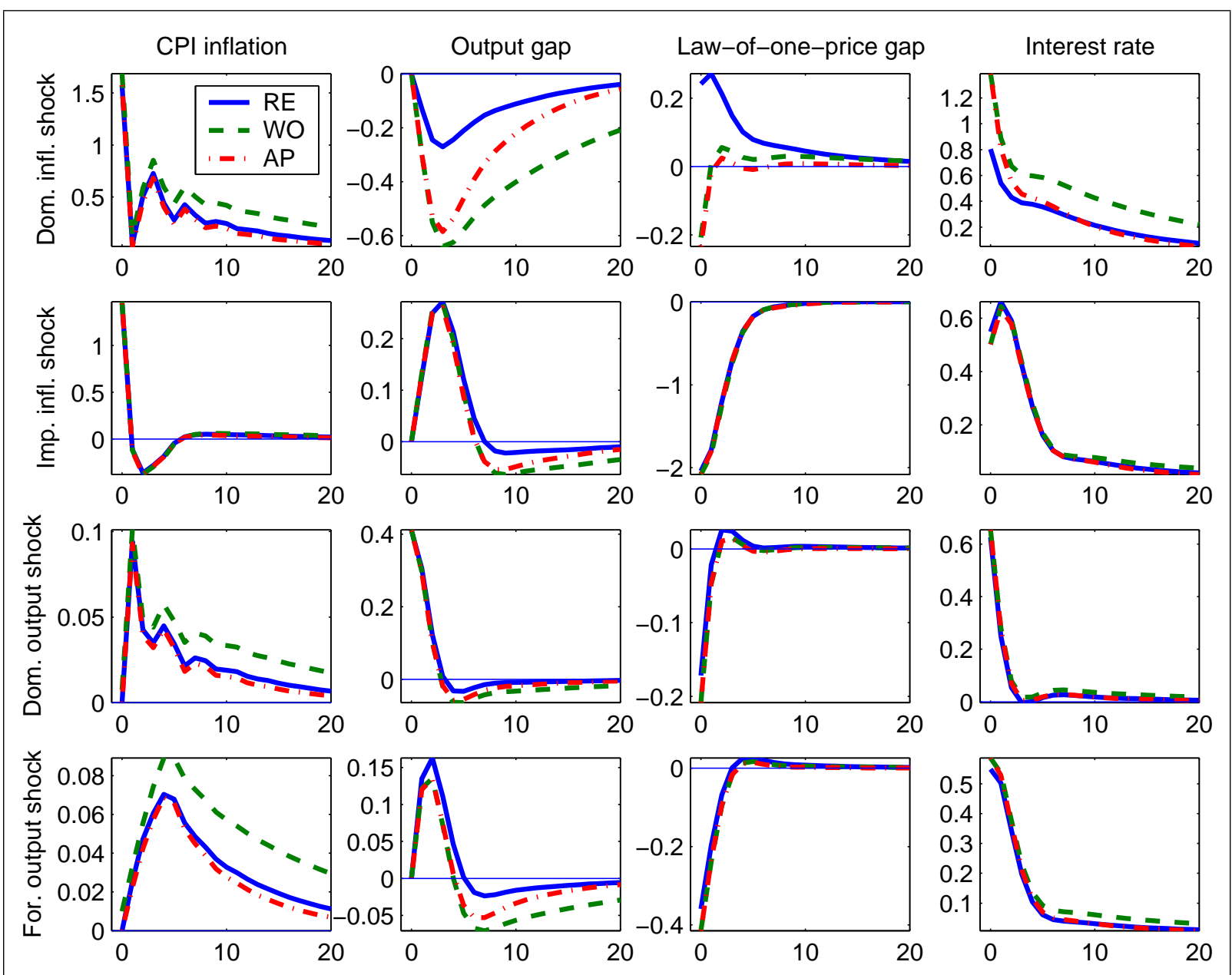

Note: The figure shows impulse responses of key variables to shocks (of one standard deviation) in the open-economy model without exchange rate shocks when monetary policy and specification errors are set with discretion. The preference for robustness is chosen to produce a detection error probability of 0.10. 
Figure 4: Impulse responses in open-economy model with all shocks

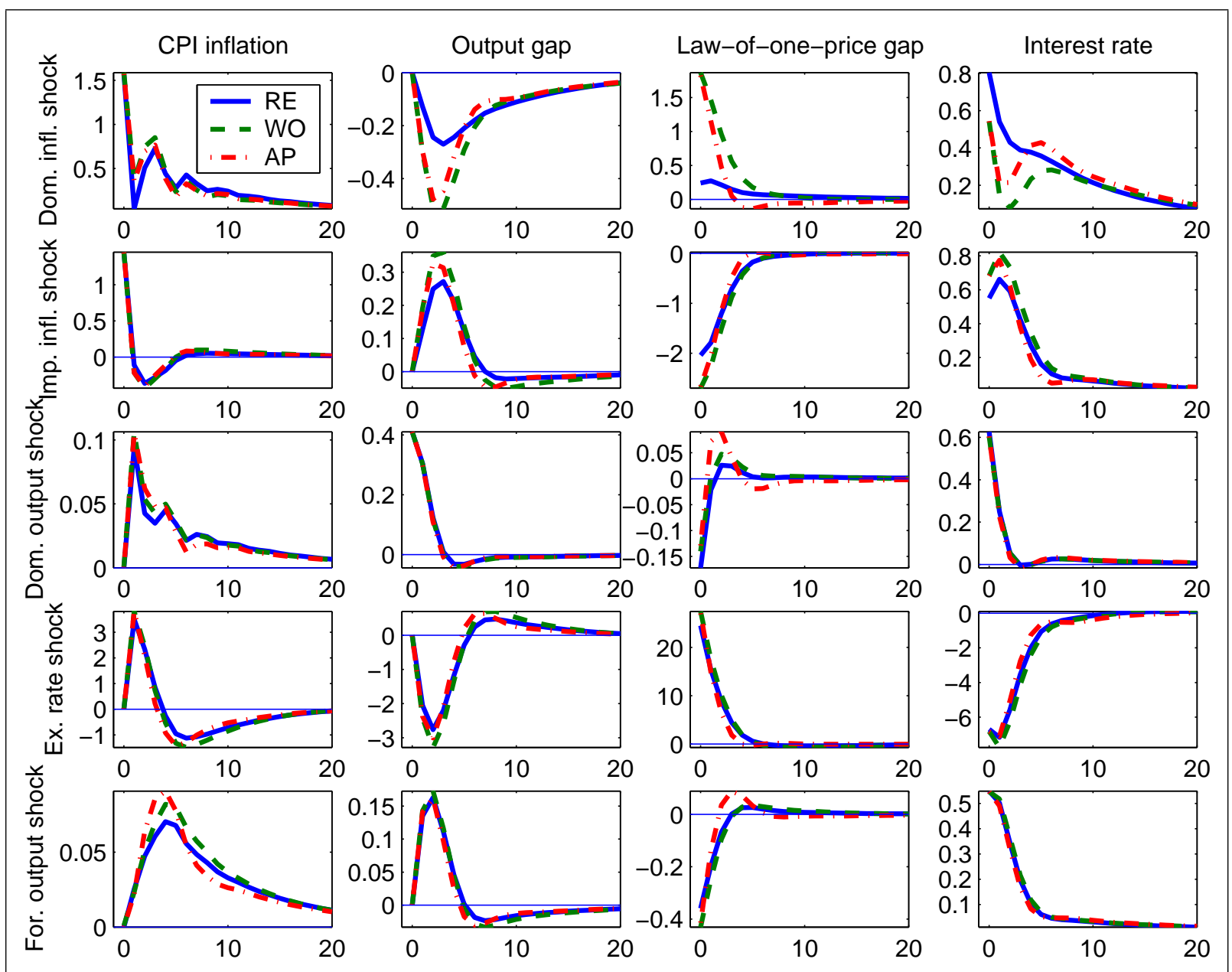

Note: The figure shows impulse responses of key variables to shocks (of one standard deviation) in the open-economy model with all shocks when monetary policy and specification errors are set with discretion. The preference for robustness is chosen to produce a detection error probability of 0.10 . 